\title{
Key Planning Factors For Recovery from Chemical Terrorism Incidents
}

\author{
Donna Edwards, Paula Krauter, Dave Franco, Mark Tucker
}

Prepared by

Sandia National Laboratories

Albuquerque, New Mexico 87185 and Livermore, California 94550

Sandia National Laboratories is a multi-program laboratory managed and operated by Sandia Corporation, a wholly owned subsidiary of Lockheed Martin Corporation, for the U.S. Department of Energy's

National Nuclear Security Administration under contract DE-AC04-94AL85000. 


\section{Issued by Sandia National Laboratories, operated for the United States Department of Energy by Sandia Corporation.}

NOTICE: This report was prepared as an account of work sponsored by an agency of the United States Government. Neither the United States Government, nor any agency thereof, nor any of their employees, nor any of their contractors, subcontractors, or their employees, make any warranty, express or implied, or assume any legal liability or responsibility for the accuracy, completeness, or usefulness of any information, apparatus, product, or process disclosed, or represent that its use would not infringe privately owned rights. Reference herein to any specific commercial product, process, or service by trade name, trademark, manufacturer, or otherwise, does not necessarily constitute or imply its endorsement, recommendation, or favoring by the United States Government, any agency thereof, or any of their contractors or subcontractors. The views and opinions expressed herein do not necessarily state or reflect those of the United States Government, any agency thereof, or any of their contractors.

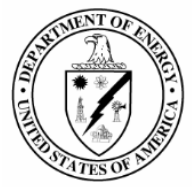

$$
\text { rs. }
$$




\title{
Key Planning Factors For Recovery from Chemical Terrorism Incidents
}

\author{
Donna Edwards Paula Krauter, Dave Franco, Mark Tucker
}

Sandia National Laboratories

P.O. Box 969

Livermore, California 94551-MS9003

\begin{abstract}
A chemical warfare agent incident has the potential to disrupt life and business in a community through human and animal casualties and land and facility contamination. Confusion and delay in response and communication can exacerbate the problem and erode public confidence. Conversely, advance planning, with particular emphasis on the Key Planning Factors identified in this document, could substantially aid the recovery process by decreasing the recovery timeline and costs, improving public health and safety, and addressing major resource limitations and critical decisions.
\end{abstract}

Further dissemination only as authorized to U.S. Government agencies and their contractors; other requests shall be approved by the originating facility or higher DOE programmatic authority. 


$$
\text { per }
$$









\section{Acknowledgements}

Funding and direction were provided by the Department of Homeland Security, Science and Technology Directorate, Wide Area Recovery and Resiliency Program under the guidance of Chris Russell and Lori Miller.

The modeling and analysis provided by this report could not have been possible without extensive interactions with the Colorado state and local public safety agencies in an effort led by Gary Breese and workshop facilitation provided by Cubic and Sandia National Laboratories and Lawrence Livermore National Laboratories.

Additional thanks are due to Nate Gleason and Todd West, Sandia National Laboratories, for their technical review and comments and to Holly Larsen, Sandia National Laboratories, for her editorial review. 


\section{Table of Contents}

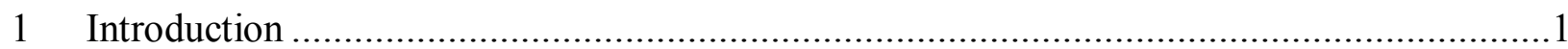

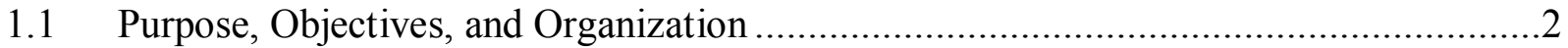

1.2 Recovery Support Functions, Recovery Gaps, and Key Planning Factors ....................3

1.3 Limitations and Assumptions .......................................................................4

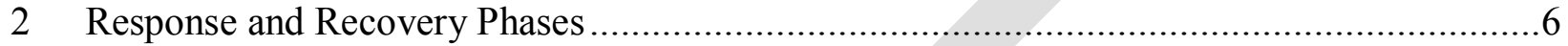

3 Chemical Warfare Agent Threat Scenario ...........................................................

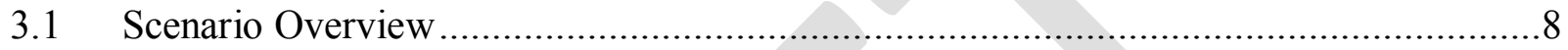

3.2 Short-Term Response and Recovery.......................................................... 10

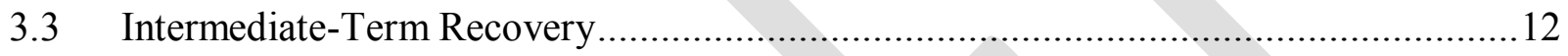

3.4 Long-Term Recovery ......................................................................... 16

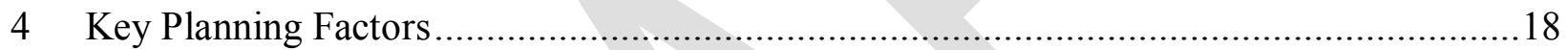

4.1 Public Health and Medical Priorities .................................................................. 19

4.2 Operational Guidelines...........................................................................20

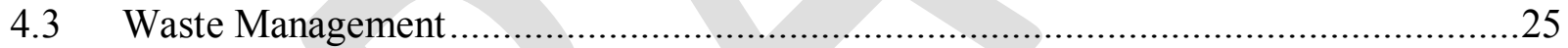

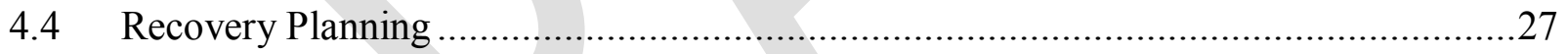

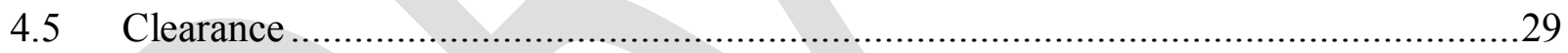

4.6 Recovery Planning for CBR and All-Hazards.................................................30

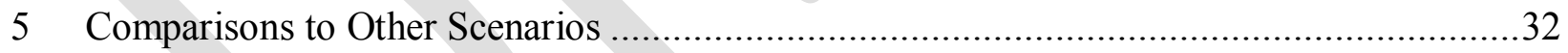

5.1 Recovery from CBR Events versus Traditional All-Hazards Events .........................32

5.2 Recovery from CWA Events versus Radiological or Biological Events .....................33

5.3 Differences between the Example Scenario and Other CWA Scenarios .....................33

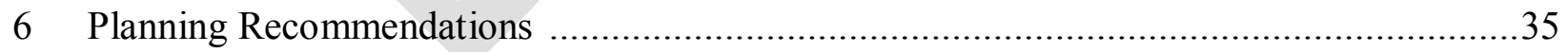

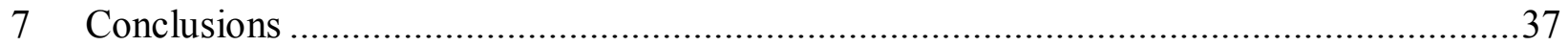

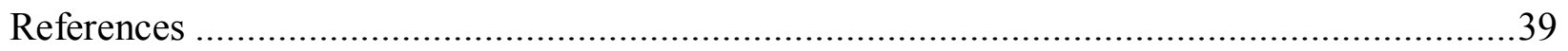

Appendix 1: Recovery Support Functions, Core Capabilities, and Key Planning Factors ...........43

Appendix 2: Wide-Area Response and Recovery Phases ................................................45

Appendix 3: Comparison of CBR Scenarios in Key Planning Factors for Recovery Document Set 51 
Appendix 4: Chemical Agent Toxicity .....

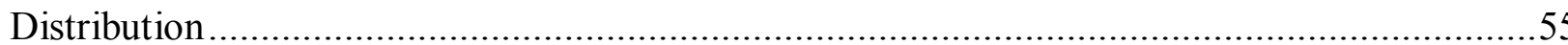

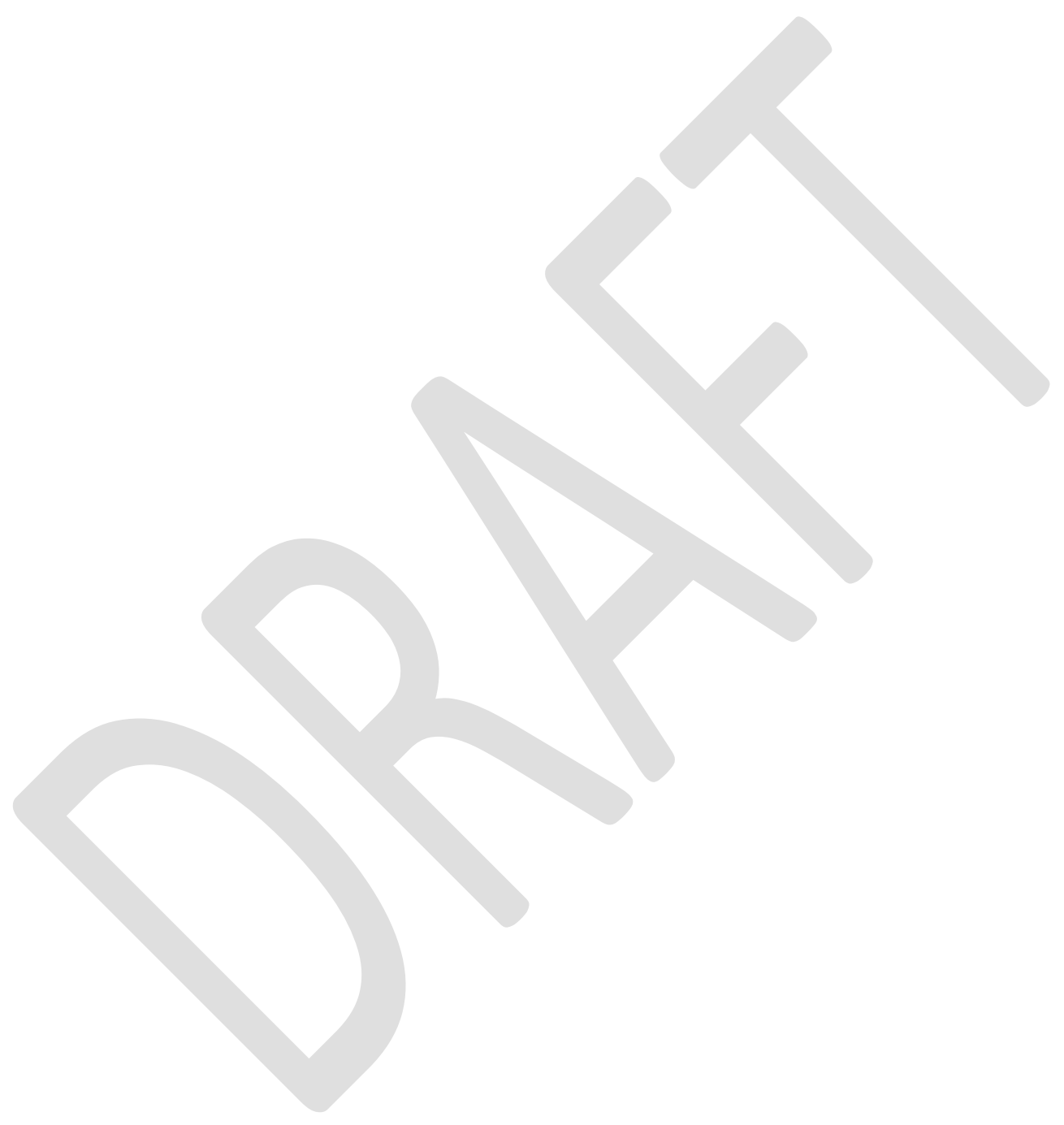




\section{Nomenclature}

\begin{tabular}{ll} 
CBR & chemical, biological, or radiological \\
CDC & Centers for Disease Control and Prevention \\
ChemOTD & Chemical Operational Technology Demonstration \\
CONOPS & concepts of operation \\
CWA & chemical warfare agent \\
DHS & Department of Homeland Security \\
EMT & emergency medical technician \\
EOC & Emergency Operations Center \\
EPA & Environmental Protection Agency \\
FEMA & Federal Emergency Management Agency \\
HazMat & hazardous materials \\
HD & sulfur mustard \\
HL & Agent Yellow \\
ICS & Incident Command System \\
IMAAC & Inter-Agency Modeling and Atmospheric Assessment Center \\
L & Lewsite \\
NCP & National Contingency Plan \\
NDRF & National Disaster Recovery Framework \\
NPDES & National Pollutant Discharge Elimination Program \\
NPG & National Preparedness Goal \\
OPCW & Organization for Prohibition of Chemical Weapons \\
POTW & Publicly Owned Treatment Works \\
RCRA & Resource Conservation and Recovery Act \\
RSF & Recovery Support Functions \\
\hline
\end{tabular}


SME $\quad$ subject matter expert

UC Unified Command

WARRP Wide-Area Recovery and Resiliency Program 


\section{Introduction}

The United States has made significant progress in building and sustaining its national preparedness (Federal Emergency Management Agency (FEMA), 2011) against the threats and hazards that pose the greatest risk to the security of the country. However, a wide-area chemical, biological, or radiological (CBR) incident will pose serious challenges for recovery of the contaminated region. As noted in the National Preparedness Goal (NPG) (FEMA, 2011), recovery requires timely restoration, strengthening, and revitalization of infrastructure; implementation of long-term housing solutions; a sustainable economy; and strengthening of the health, social, cultural, historic, and environmental fabric of communities affected by the incident (FEMA, 2011). Fulfilling these requirements during a wide-area CBR incident will be challenging and complex.

As an example of the challenges in a relatively small chemical incident, on January 6, 2005, a freight train accident in South Carolina released 70 tons of pressurized chlorine liquid, a toxic industrial chemical. This incident, although small on the scale of potential CBR incidents, was one of the largest community exposures of a fast-acting, deadly inhalant in modern history, leaving 9 people dead and 71 with acute health effects. It also required a one-mile wide radius evacuation that affected 5,400 residents for up to 13 days. The rail line was shut down for 23 days (the time required to drain liquid chlorine from railcars and remove damaged rolling stock), creating severe economic consequences to the railroad (see Figure 1). The recovery from this toxic industrial chemical event had commonalities with recovery from a chemical warfare agent event.

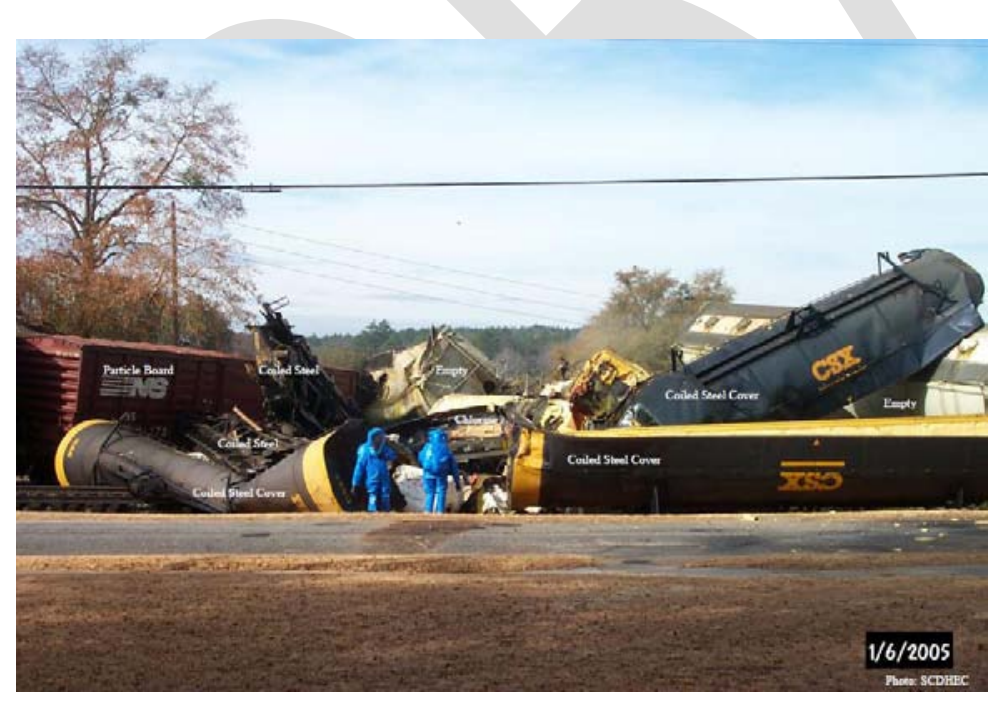

Figure 1. Site of a 2005 freight train accident in South Carolina

January 6, 2005 a freight train accident in South Carolina released 70 tons of pressurized chlorine liquid. Photo source: SCDHEA, 1/6/2005. 
This document identifies and describes selected Key Planning Factors to aid in recovery planning for wide-area chemical warfare incidents. Key Planning Factors are issues that are most important to examine prior to the occurrence of an event. In particular, Key Planning Factors are considerations that can substantially influence the recovery process by increasing the rate of recovery, reducing recovery costs, improving public health and safety, addressing major resource limitations, or informing critical decisions. Therefore, incorporating Key Planning Factors specific to chemicals into recovery plans will increase resiliency.

Key Planning Factors for chemical warfare agent (CWA) incident recovery will differ from those for radiological and biological incident recovery in areas related to the fate and transport of the agent. For instance, the contaminated area for any agent - chemical, biological, or radiological would depend on the method of agent distribution and the agent persistence (persistence refers to the length of time an agent remains harmful to humans and/or other forms of life - both in terms of its toxicity and its location), leading to wide variation amongst the threat types and the particular agents. CWAs that are relatively volatile and not persistent would leave less contamination, as would biological agents that degrade rapidly in the environment. On the other hand, persistent CWAs and spore-forming biological agents (B. anthracis) would potentially have a larger area of contamination. Chemical warfare agents can be in liquid or gaseous forms and have different chemical compositions with a wide range of volatilities and viscosities. Because of these properties, CWAs will penetrate into some building materials more readily than others, and different CWAs will persist in the environment for different time periods.

This document is a companion document to three other Key Planning Factors documents. Two of these documents focus on Key Planning Factors for biological and radiological incidents, and the third describes considerations for critical infrastructure and economic impact. All four documents build upon numerous technical and policy guidance documents on consequence management, response, and recovery, including the National Disaster Recovery Framework (FEMA, 2011), National Preparedness Goals (FEMA, 2011), Presidential Policy Directive 8: National Preparedness (PPD-8), and the Remediation Guidance for Major Airports After a Chemical Attack, (DHS 2011) (FOUO).

\subsection{Purpose, Objectives, and Organization}

The primary purpose of the Key Planning Factors for Recovery from Chemical Terrorism Incidents document is to motivate and inform regional recovery planning for a wide-area CWA incident. To achieve this goal, this document identifies and describes a selected number of Key Planning Factors critical to wide-area CWA incident recovery planning.

The objective of this document is to provide a concise technical resource that complements existing guidance and helps recovery planners prepare for issues that may significantly limit recovery success. This document is intended to serve as a catalyst for planning to address these issues prior to a CWA event, but does not seek to identify all the possible challenges that may arise in such an event. 
Audiences for this document include local, regional, state, and federal stakeholders within the emergency preparedness community involved in CWA response and recovery planning and in operational activities.

This document has been organized to illustrate the response and recovery processes associated with a wide-area CWA incident and identify the Key Planning Factors involved in such processes. To this end, Section 1 describes the document purpose and objectives, defines the term Key Planning Factor, and discusses limitations and assumptions. Section 2 provides a general background on the National Disaster Recovery Phases and applies those phases to a wide-area CWA incident. Section 3 offers an illustrative narrative scenario to identify and describe the activities related to recovery. Section 4 identifies and describes the Key Planning Factors for CWA incidents. Section 5 provides comparisons to other scenarios, discussing the differences between recovery from CBR events versus traditional all-hazards events; differences between recovery from CWA events versus radiological or biological events; and differences between the example scenario and other possible CWA scenarios. Section 6 provides planning recommendations and a conclusion.

Four appendices follow: the first describing the relationships among the National Disaster Recovery Framework Recovery Support Functions, the National Preparedness Goal Core Recovery Capabilities, and the WARRP Key Planning Factors, the second describing the widearea response and recovery phases, the third comparing the WARRP chemical, biological, and radiological scenarios, and the fourth providing information about chemical agent toxicity.

\subsection{Recovery Support Functions, Recovery Gaps, and Key Planning Factors}

\section{Recovery Support Functions}

The whole community concept described in the National Disaster Recovery Framework (NDRF) (Federal Emergency Management Association, 2011) and the National Preparedness Goal (FEMA, 2011) recognizes that all stakeholders in a community (that is, volunteer-, faith-, and community-based organizations, the private sector, local and regional governments, and the public) are needed to effectively recover from a catastrophic event. To facilitate pre-disaster planning and foster coordination among state and federal agencies, nongovernmental partners, and stakeholders, the NDRF identifies functional areas of assistance, known as the Recovery Support Functions (RSFs). The RSFs are:

- Community Planning and Capacity Building

- Economic

- Health and Social Services

- Housing

- Infrastructure Systems

- Natural and Cultural Resources 


\section{Key Planning Factors}

For a wide-area CBR incident, each RSF will have unique technical and operational issues that require particular focus or effort. The Key Planning Factors identified in this document are threat-specific and derived from several sources, including from a comprehensive literature review and from facilitated discussions in the Wide-Area Recovery and Resiliency Program (WARRP) Chemical, Biological, and Radiological Workshop ${ }^{1}$ that revealed a number of critical considerations. Another important source was the WARRP systems study sponsored by the Department of Homeland Security in 2012 (Einfeld, et al., 2012). Drawing from a broad perspective - including regional risk management, site-specific recovery, and long-term public health issues developed by more than 100 local, state, federal and private stakeholders - the WARRP study identified key performance gaps and critical considerations that limited recovery effectiveness while increasing remediation timelines and recovery costs. The relationships among the NDRF Recovery Support Functions, the NPG Core Recovery Capabilities, and the Key Planning Factors are shown in Appendix 1.

The Key Planning Factors discussed here meet several criteria. They are all pre-incident planning activities, can be initiated by state and local governments, and have the potential to substantially influence the recovery process by a number of means: increasing the rate of recovery, reducing recovery costs, improving public health and safety, addressing major resource limitations, or informing critical decisions. The Key Planning Factors presented here do not encompass the totality of the planning process or all of the issues that need to be addressed. Instead, this document clarifies some of the issues that will benefit most from pre-disaster community planning.

\subsection{Limitations and Assumptions}

This document does not describe how to prepare a plan for CBR response and recovery or provide a playbook on how to respond during a CBR event. ${ }^{2}$ Rather it identifies Key Planning Factors that, if addressed, will provide significant value when preparing such a plan or playbook. In addition, it provides references to key resource documents that will enable readers to further research a particular subject matter.

To provide context and increase understanding of the Key Planning Factors, this document presents a chemical warfare agent scenario featuring Agent Yellow, a blister agent. Agent Yellow is a mixture of persistent chemicals with low volatility, low water solubility, and strong sorption into certain materials. As a result, remediating urban areas contaminated with Agent Yellow will be challenging. The Key Planning Factors identified within this document address many of these challenges. The document also discusses instances when use of a different CWA

\footnotetext{
${ }^{1}$ The first workshop conducted under the WARRP Knowledge Enhancement Working Group, was held in Denver, Colorado, on January 30-31 of 2012. Forty state, local, and federal agencies collaborated in the identification of critical CBR considerations to support development of a UASI-level all-hazard and WMD (?) response and recovery framework.

${ }^{2}$ Planning guidance may be found in the All-Hazards Plan and CBR Annexes (REF).
} 
would impact the Key Planning Factors. For example, pre-planning to rapidly identify an agent and initiate appropriate public health responses may become more important in the presence of an extremely toxic but less persistent agent, such as sarin. 


\section{Response and Recovery Phases}

The National Disaster Recovery Framework phases provide a useful tool for organizing the major activities associated with wide-area CBR consequence management. This framework identifies three primary phases of action following a disaster incident-short-, intermediate-, and long-term - that can overlap, sometimes considerably. As shown in Figure 2, actions intended to address long-term recovery can actually begin during the short-term phase.

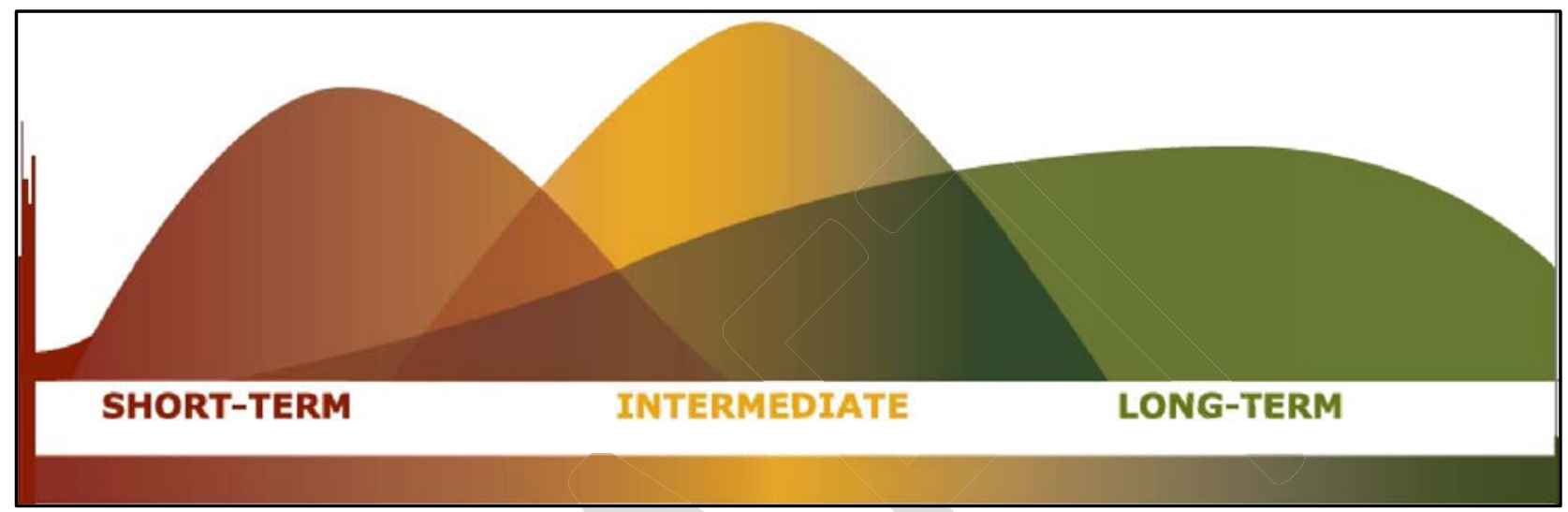

Figure 2. Overlap in the short-, intermediate, and long-term phases of incident recovery (NDRF)

For a wide-area CWA incident, this timeframe could be compressed into a matter of hours or could last days or weeks. For example, on March 20, 1995, attackers released the nerve agent sarin through several crude devices placed in railcars in Tokyo subway stations. This attack resulted in 12 deaths, 54 individuals with critical effects, and 984 individuals with moderate effects of the agent. In addition, more than 4,000 people were examined by medical staff and released. As catastrophic as this attack was, the entire timeline, from release of sarin in the railcars to resumption of full service of the Tokyo rail system, was only 21 hours. This compressed timeframe was due to the high volatility of sarin $\left(16,091 \mathrm{mg} / \mathrm{m}^{3}\right.$, as opposed mustard, which has a volatility of $610 \mathrm{mg} / \mathrm{m}^{3}$ ). Other warfare agent scenarios, such as the Agent Yellow scenario described within, will result in longer timelines due to the agent persistence.

The Department of Homeland Security's (DHS's) Wide-Area Recovery and Resiliency Program defines the response and recovery activities as follows:

- Notification

- First Response

- Risk Assessment

- Planning

- Characterization

- Decontamination

- Clearance

- Restoration and Reoccupation 
This list of activities was developed by interagency working groups from agencies such as the Environmental Protection Agency (EPA), Centers for Disease Control (CDC), DHS and others. These activities and the relationship to the National Disaster Recovery Phases are discussed in Appendix 2 and are used to describe the response to the example scenario presented in the next section. 


\section{Chemical Warfare Agent Threat Scenario}

To introduce Key Planning Factors for recovery, an illustrative CWA release scenario explores what may occur after an aerosol dispersal of a chemical warfare agent. This scenario focuses on the dispersal of Agent Yellow (HL) in downtown Denver, Colorado. Agent Yellow is a mixture of the blistering agents Lewisite (L) and Sulfur Mustard (HD) that produces the types of blisters shown in Figure 3. Although the scenario is very specific, its associated Key Planning Factors are expected to apply to releases of other types of CWA releases in other urban areas. However, certain Key Planning Factors may become more or less important, depending on the physical and chemical properties of the agent used. The sections

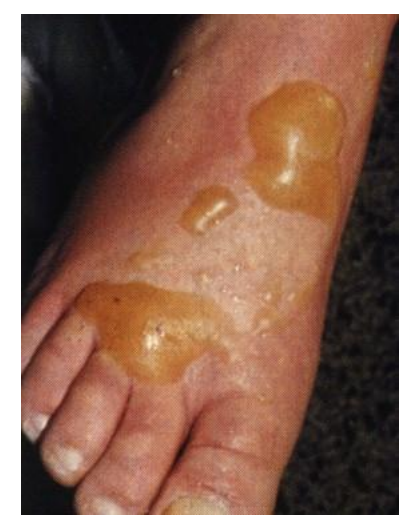

Figure 3. Skin affected by mustard gas

Source:

http://trcs.wikispaces.com Imustard\%20gas(4)) below describe the scenario and the recovery, organized in accordance with the NDRF phases (short-, intermediate-, and long-term) and the WARRP response and recovery activities (notification, first response, characterization, decontamination, clearance, and restoration and reoccupation). The Key Planning Factors will be introduced through the discussion of response activities to this scenario..

\subsection{Scenario Overview}

On July 4, an unspecified number of terrorists convene in a remote air field west of Denver, Colorado. They equip a small agricultural aircraft with the CWA Agent Yellow. Shortly thereafter, the plane takes flight and sets course towards Denver's Coors Field baseball stadium, where a game between the Colorado Rockies and the San Francisco Giants is about to begin.

While flying in an eastward direction on a half-mile path just to the north of Coors Field, the pilot reduces speed and releases the CWA payload. A significant fraction of the agent plume travels directly into the open air stadium. The remaining fraction is carried by the wind into the surrounding area and infrastructure of downtown Denver. The plume travels a distance of over five miles. Figure 4 shows the CWA plume on a map.

More than 50,000 people come into direct contact with, or breathe vapors or droplets of, the Agent Yellow spray and begin showing an array of symptoms: difficulty breathing, eye irritation, loss of coordination, nausea, or a burning sensation in the nose, throat, and lungs (see Appendix 4 for information on CWA toxicity). The presence of many dead insects or birds also indicates a chemical warfare agent release.

Thousands attempt to flee the stadium, and many are injured in the rush to escape the CWA plume. Elsewhere, persons run into nearby buildings and numerous auto accidents occur on the roadways surrounding the stadium. 911 receives hundreds of calls from individuals experiencing 
burning sensations and blistering of the skin. Hospital and medical staff are caught unaware as victims of the terrorist attack arrive requesting immediate attention.

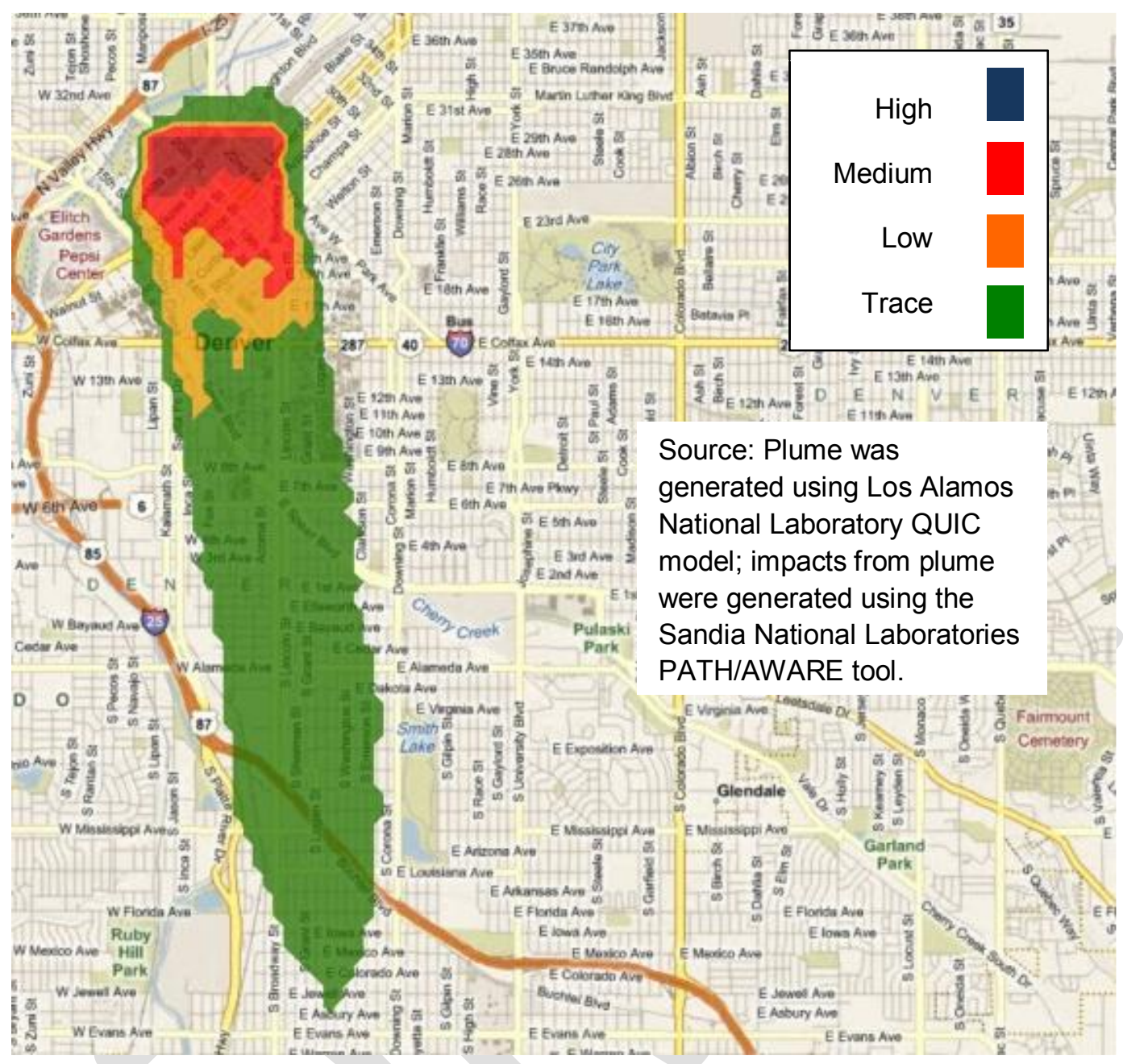

Figure 4. Chemical warfare agent scenario plume

\section{Characteristics of Chemical Warfare Agents}

Chemical warfare agents are often categorized as persistent or non-persistent, which describes how long the chemical remains toxic and if it remains in a location to cause potential harm. A persistent CWA can remain in a liquid state and present a hazard for 24 hours or more; a nonpersistent CWA will volatilize or degrade from a liquid state in minutes to hours, quickly losing toxicity (USACHPPM 2008a, Watson et al., 2011) (Table 1). For example, due to its volatility, gasoline will evaporate more quickly than oil under the same environmental conditions. Factors that influence volatilization or degradation rates include the ambient temperature, the wind speed, and the surface upon which the agent settles. Agent Yellow is relatively persistent; at $50^{\circ} \mathrm{F}$, the evaporation time of mustard is about 100 hours on sandy surfaces and about 12 hours on non-porous surfaces. 
Table 1. Persistence of some chemical warfare agents

\begin{tabular}{|c|c|c|c|c|c|c|c|c|}
\hline \multirow[b]{2}{*}{ Examples } & \multicolumn{2}{|c|}{ Nerve Agents } & \multicolumn{2}{|c|}{$\begin{array}{l}\text { Blister Agents } \\
\text { (injure skin, eyes, } \\
\text { and airways) }\end{array}$} & \multicolumn{2}{|c|}{$\begin{array}{l}\text { Blood Agents } \\
\text { (cause blood changes } \\
\text { and heart problems) }\end{array}$} & \multicolumn{2}{|c|}{ Choking Agents } \\
\hline & Sarin & $V X$ & Mustard & Lewisite & $\begin{array}{l}\text { Hydrogen } \\
\text { Cyanide }\end{array}$ & $\begin{array}{l}\text { Cyanogen } \\
\text { Cyanide }\end{array}$ & Chlorine & Phosgene \\
\hline Persistence* & $\begin{array}{c}\text { Non- } \\
\text { persistent } \\
\text { (min to hrs) }\end{array}$ & $\begin{array}{l}\text { Persistent } \\
\text { (> } 12 \mathrm{hrs})\end{array}$ & \multicolumn{2}{|c|}{ Persistent } & \multicolumn{2}{|c|}{ Non-persistent } & \multicolumn{2}{|c|}{$\begin{array}{l}\text { Non-persistent; } \\
\text { vapors may hang in } \\
\text { low areas }\end{array}$} \\
\hline
\end{tabular}

From http://www.dhs.gov/files/publications/gc 1243884402361.shtm\#table1

*The length of time a chemical warfare agent remains at toxic levels

As noted above, Agent Yellow comprises Lewisite and Mustard, typically in a ratio of 63\% L to 37\% HD. Lewisite and Mustard are persistent agents with low volatility, low water solubility, and strong sorption into certain types of materials. Both cause severe blistering of skin and other tissue, with Lewisite causing immediate effects and Mustard causing delayed effects (Figure 5). Eye exposure can lead to temporary blindness, and severe damage to the eye may be present for a long time after the exposure. Agent Yellow can also damage the immune system and increase the risk of cancer. Likely future health effects from high levels of exposure include kidney and liver damage, as well as chronic respiratory diseases.
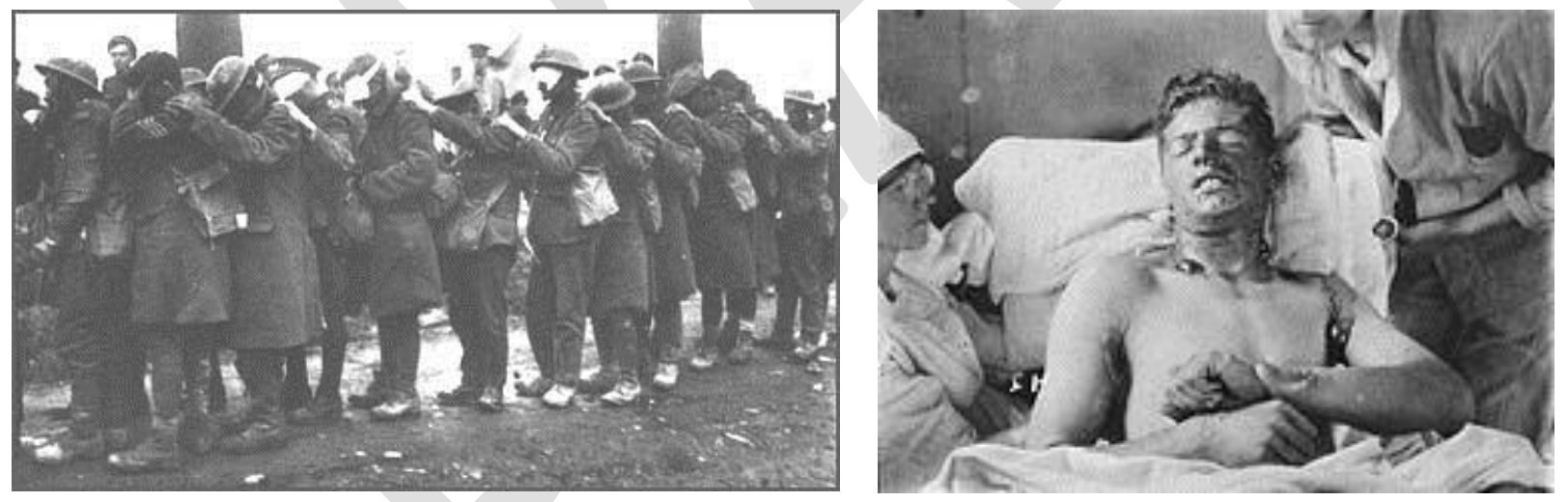

Figure 5. Soldiers in World War I exposed to Sulfur Mustard

Photo source: http://en.wikipedia.org/wiki/Chemical warfare

\subsection{CWA Threat Scenario Short-Term Response and Recovery}

\section{Notification Phase}

As news of the terrorist attack rapidly spreads, hazardous material (HazMat) units are deployed to the stadium and downtown area to conduct chemical tests to identify the hazard agent. 
Simultaneously, Emergency Operations Centers (EOCs) are activated across local, state, and federal jurisdictions. The Colorado National Guard is activated.

A Unified Command (UC) is established to direct response and recovery operations, including forensic analysis and public health risk mitigation. Due to concerns of a second attack in Denver or elsewhere in the nation, aircraft across the nation are grounded and all security organizations and personnel put on high-alert. Information gathering and dissemination to all relevant agencies are the main tasks.

\section{First-Response Phase}

Local emergency medical services and first response teams are activated and arrive on scene at the stadium. Operations to rescue and treat individuals still inside the stadium begin immediately, though the cumbersome personal protection equipment (PPE) required for the unknown HazMat threat slows down operations. Personnel decontamination capabilities are stood up and staged near the Denver stadium. However, these resources are limited, and the demand greatly exceeds the supply.

Despite significant uncertainty regarding the exact area of contamination, downtown Denver is closed over an area of about 2 square miles:

- From the City of Cuernavaca Park on the north to West $8^{\text {th }}$ Avenue on the south

- From I-25 on the west to Lawson and Benedict Fountain Parks on the east

There is disagreement among decision-makers and the public over whether inhabitants inside the closed area should remain sheltered-in-place or evacuate. At issue are the differences in exposure caused by each option and whether additional movement would spread the contamination further.

\section{Key Planning Factor: Establish protocols for control of agent fate and transport after the initial event}

Established protocols to control the transport of a persistent agent can help prevent additional exposures and limit further spread of the agent.

Local first response teams, unfamiliar with CWA characteristics and unprepared to test for CWAs, struggle with agent identification. The National Guard Civil Support Team is called in and identifies the CWA as Agent Yellow, a persistent blister agent. Communications are dispatched to inform members of the UC and the public of the agent identification and its characteristics. 


\section{Key Planning Factor: Establish protocols for first responders to rapidly identify the chemical warfare agent and determine its volatility and persistence}

Agent identification precedes initiation of public health response measures; control of agent transport requires information about volatility and persistence.

Due to concerns of contamination outside of the area of closure, critical assets in the area of suspected contamination are closed, including the Denver Mint, Coors Field, Pepsi Center, the Metropolitan State College of Denver, and Invesco Field Mile High.

In parallel, members of the population continue to flood nearby hospitals, requesting immediate assistance. More than 60 primary care clinics, including the Aurora Urgent Care facility, Saint Joseph Hospital, and Plasma Holdings LLC Blood Bank, are potentially contaminated from either victims spreading the agent or the plume itself. Some medical workers, including ambulance drivers and EMS personnel, become ill from exposure to the agent as it off-gases from contaminated victims. Many other members of the population become exposed through secondary contamination.

\section{Key Planning Factor: Establish plans for public health response specific to chemical warfare agents}

Throughout the initial phases, plans for public health response to specific chemical warfare agents will protect first responders and guide medical countermeasures.

Public fears over unidentified areas of contamination remain high, and security continues to be provided by the Denver Police and Colorado National Guard. In addition, there is concern about the long-term effects of exposure.

\subsection{CWA Threat Scenario Intermediate-Term Recovery}

The Unified Command has established multiple working groups, including a public health working group and a recovery stakeholders working group, to support recovery operations and planning. Selection of participants (e.g., subject matter experts and organizational representatives) for these groups was contentious, and several organizations are already declaring the recommendations of these working groups biased and tainted. 


\section{Key Planning Factor: Identify and create Stakeholder Working Groups}

Pre-identifying participants streamlines and adds transparency to the process, and aids in gaining buy-in from the public.

\section{Risk-assessment}

Many areas of contamination have been identified and cordoned off. However, new isolated —ht spots" continue to be found regularly. Outside of the cordoned zone, areas are characterized through a slow and cumbersome process, and people are gradually being allowed back to residences in areas confirmed not to be a health risk. However, more than 5,000 people remain in temporary shelters.

\section{Key Planning Factor: Develop protocols to determine the extent of contamination}

Established protocols can help streamline the identification of contaminated zones, knowledge that is crucial to both public health response and recovery.

Pre-incident risk assessments to determine the health risk and dose-response for Agent Yellow are insufficient. New assessments are ongoing and the Public Health working group continues to develop thresholds based on the limited data that is available. Furthermore, the risk of contamination spreading through people and goods is considered significant and national-level warnings are issued for all goods and people that have traveled through the area or contacted people or goods from the area. Information to the public from official sources is sporadic and changing due to the evolving information on risk and on the lack of a clear communication plan. Independent -experts" also continue to inform the public through social and network media. These assessments often lack credibility, are conflicting, and contribute to public unrest.

\section{Key Planning Factor: Develop public messaging and communication strategies specific to a CWA incident}

Predefined strategies can aid timely and accurate communication and build public confidence in recovery efforts.

\section{Planning}

Planning efforts are underway to identify and acquire resources from neighboring jurisdictions to support remediation operations. Those resources that are available are in short supply, and many 
residential and commercial facilities remain closed, awaiting screening for contamination, decontamination verification, or clearance. In addition, businesses outside the area that normally do business with the affected region remain closed due to lack of demand or concerns for public health.

Resources to conduct characterization, decontamination, and clearance activities are insufficient to meet the region's needs, and the competition for these resources is increasing within the public and private sectors.

\section{Key Planning Factor: Determine requirements for, and sources of, the resources for recovery from a CWA incident}

Pre-identified and pre-arranged agreements with neighboring jurisdictions can facilitate this process and speed the acquisition of the resources required for recovery.

Decision-makers are coming under intense scrutiny for nearly every decision about prioritization and resource allocation. (Note that advance planning for prioritization and resource allocation decisions is discussed in more detail in the companion document, Recovery from Chemical, Biological, and Radiological Incidents: Critical Infrastructure and Economic Impact Considerations.)

Waste management continues to be a significant challenge. At the operational level, controls on staging areas for containment, segregation, and decontamination are being developed. However, it is unlikely that waste disposal sites will be identified in the foreseeable future. In the meantime, the region is facing increased numbers of illicit or roadside dumping incidents. Plans to manage this activity need to be developed.

\section{Key Planning Factor: Establish waste management plans for CWA incident-specific waste, including both contaminated and decontaminated materials}

Pre-identified and pre-arranged agreements with disposal facilities can speed the removal and management of waste.

Furthermore, concerns are growing over the cost of remediation operations and the economic impact of the loss of business and conventions. Chokepoints in the remediation process are limiting progress, and many stakeholders in the public and private sector are asking how long remediation operations will take. At this time, no definitive answer has been given. 


\section{Characterization}

Characterization of the potentially contaminated environment to determine remediation requirements relies on sampling technology that is laborious and slow. Existing field technologies may lack the appropriate level of sensitivity to support wide-area characterization of the CWA incident in an urban environment. Additionally, the safety for those conducting characterization activities is a concern.

\section{Decontamination}

Characterization of the contaminated area shows that decontamination of hundreds of facilities and areas is required. These areas include both public and private spaces and comprise commercial, residential, and industrial infrastructure. Decontamination of the Agent Yellow is challenging due to the persistent nature of the blister agent. Because different surfaces require different decontaminants, multiple decontamination technologies will likely be required. The fact that some surfaces will be nearly impossible to decontaminate will lead to complex decisions on decontamination versus disposal.

Decontamination is being accomplished primarily through hydrolysis or oxidation, using bleach, caustic (sodium hydroxide), or hydrogen peroxide-based solutions. Over time, the hydrolysis products from Lewisite will be transformed into both organic and inorganic forms of arsenic, leading to environmental concerns. In addition, decontamination on porous and/or permeable surfaces may be difficult due to the decontaminant's inability to reach the agent. The amount of waste generated by various decontamination processes is also a concern. Some subject matter experts state that handling waste generated by decontamination processes is more problematic than the actual decontamination process itself. Efforts to assess the amount of waste generated by various decontamination processes are underway.

\section{Key Planning Factor: Establish a decision-making process to select among environmental remediation options}

Advance planning can facilitate the time-consuming and complex process of recovery decision-making.

Economic impacts during decontamination might include disruption to lives and livelihoods. An attack on a food or agricultural crop could result in long-lasting economic impact for suppliers and their communities, as well as consumers.

\section{Clearance}

Re-use and re-occupancy decisions for both indoor and outdoor areas depend on health-riskdependent clearance processes and goals. These goals drive recovery costs and timelines and represent a difficult trade-off between health risk concerns and regional economic recovery concerns: the more stringent the clearance goals, the more extensive the decontamination process 
and clearance sampling, the longer the cost and timeline. Table 2 is presented as an example of potential pre-planning clearance goals for civilians.

\section{Key Planning Factor: Establish a process to develop clean-up and clearance goals specific to CWA-incident remediation}

Clean-up and clearance goals drive the recovery costs and timelines.

Table 2. Percutaneous vapor exposure guidelines for (military) CWA personnel escape from selected chemical weapons agent and toxic industrial chemical atmospheres, assuming respiratory protection

\begin{tabular}{lll} 
& $\begin{array}{l}\text { Reasonable maximum } \\
\text { clearance goals }(\mathbf{m g} / \mathbf{m} 3)\end{array}$ & $\begin{array}{l}\text { Alternative clearance } \\
\text { goals }(\mathbf{m g} / \mathbf{m} 3)\end{array}$ \\
CW-hr duration exposure & $>8 \mathrm{hr}$ but $<24$-hr duration exposure \\
\hline Tabun (GA) & $<0.0010 \mathrm{c}$ & $<0.0003 \mathrm{e}$ \\
Sarin (GB) & $<0.0010 \mathrm{c}$ & $<0.0003 \mathrm{e}$ \\
Soman (GD) and Cyclosarin (GF) & $<0.00050 \mathrm{c}$ & $<0.0002 \mathrm{e}$ \\
VX & $<0.000071 \mathrm{c}$ & $<0.000024 \mathrm{e}$ \\
Sulfur mustard (H/HD) & $<0.008 \mathrm{c}$ & $<0.003 \mathrm{e}$ \\
Hydrogen cyanide (AC) & $<1.1 \mathrm{~d}$ & $<0.37 \mathrm{e}$ \\
Cyanogen chloride (CK) & $<0.25 \mathrm{f}$ & $<0.08 \mathrm{f}$ \\
Phosgene (CG) & $<0.08 \mathrm{~g}$ & $<0.03 \mathrm{~g}$ \\
\hline
\end{tabular}

Ref. Watson et al., 2011a (Table 2), here shown in modified form. Please see the Watson et al. paper for the entire table with footnotes.

\subsection{CWA Threat Scenario Long-Term Recovery}

The majority of the contaminated area has been reopened, though a few isolated areas of contamination (individual buildings) remain. Most citizens have been able to return to their homes, and temporary shelters are being shut down. On the commercial side, the majority of business facilities have been cleared for use and reopened to the public. A few buildings were razed and several new construction projects are underway. The Colorado Convention Center has been cleared for use, but many events have already been cancelled and as a result, tourism is expected to be at a standstill for the rest of the year. The cost of remediation operations and the economic impact associated with the loss of business and conventions are substantial.

An economic recovery working group has been established. Members of the recovery working group seek to identify and provide government incentives to businesses and individuals willing to re-occupy areas or facilities to entice people back into the remediated buildings.

\section{Restoration and Reoccupancy}

The current focus of long-term recovery efforts is revitalizing, rebuilding, or relocating affected areas and populations. Building owners have indicated that their limit for absorbing losses is only six months - meaning that if after six months, they are not earning rent and are facing large decontamination costs, they are likely to abandon their facilities. It is clear that businesses will 
need incentives to stay and reopen in the area. Community engagement in a prioritization process for cleanup and clearance will support and increase the capability to agree and move forward.

Long-term medical and environmental monitoring plans are being developed. Most health effects from a chemical warfare attack occur quickly. Some injuries from acute exposure to CWAs, such as eye damage and chemical burns, could persist for a lifetime. Detailed information on the possibility of developing other types of health effects later in life would be made available once a specific exposure is known. Additionally, long-term public information and communication programs will aid in establishing public trust.

This example scenario has raised and illustrated the Key Planning Factors for recovery from a chemical warfare agent. The next section will examine these factors in greater detail. 


\section{Key Planning Factors}

The Key Planning Factors, introduced and illustrated in the previous section through the example scenario, have the potential to substantially influence the recovery process by increasing the rate of recovery, reducing recovery costs, improving public health and safety, and addressing major resource limitations or critical decisions. Key Planning Factors are issues that are most important to examine prior to the occurrence of an event. This document identified ten Key Planning Factors for the CWA scenario, grouped into several areas: public health and medical priorities, operational guidelines, waste management, recovery planning, clearance, and CBR and AllHazards. These factors are shown in Table 3. Detailed descriptions, significance, and references for each Key Planning Factor follow.

Table 3. Ten Key Planning Factors for recovery from a CWA incident, grouped by category

\begin{tabular}{|l|l|}
\hline Category & Key Planning Factor \\
\hline $\begin{array}{l}\text { Mublic Health and } \\
\text { Medical Priorities }\end{array}$ & $\begin{array}{l}\text { Establish plans for public health response specific to chemical warfare } \\
\text { agents }\end{array}$ \\
\hline $\begin{array}{l}\text { Operational Guidelines } \\
\text { - Establish protocols for first responders to rapidly identify the CWA and } \\
\text { determine its volatility and persistence }\end{array}$ \\
$\begin{array}{l}\text { - Develop protocols to determine the extent of contamination } \\
\text { - Develop public messaging and communication strategies specific to a } \\
\text { CWA incident }\end{array}$ \\
\hline Waste Management & $\begin{array}{l}\text { - Establish waste management plans for CWA incident-specific waste, } \\
\text { including both contaminated and decontaminated materials }\end{array}$ \\
\hline Recovery Planning & $\begin{array}{l}\text { - Establish a decision-making process to select among environmental } \\
\text { remediation options } \\
\text { - Determine requirements for, and sources of, resources for recovery from } \\
\text { a CWA incident }\end{array}$ \\
\hline Clearance & $\begin{array}{l}\text { - Establish a process to develop clean-up and clearance goals specific to } \\
\text { CWA-incident remediation }\end{array}$ \\
\hline CBR and All-Hazards & \begin{tabular}{l} 
Identify and create stakeholder working groups \\
\hline
\end{tabular} \\
\hline
\end{tabular}




\subsection{Key Planning Factors: Public Health and Medical Priorities}

\section{Key Planning Factor: Establish plans for public health response specific to chemical warfare agents}

Throughout the initial phases, plans for public health response to specific chemical agents will protect first responders and guide medical countermeasures.

\section{Description}

This Key Planning Factor focuses on the development of plans for an effective public health and medical response. This includes plans for first responder safety, medical countermeasures, and medical surge specific to various CWA types. It also involves developing concepts of operation (CONOPS), plans, and procedures using existing information on public health risk.

\section{Significance}

Unlike some potential biological or radiological attacks, a CWA attack is likely to generate immediate mass casualties. As an example, the 1995 Tokyo attacks left hundreds injured within minutes after the initial attack. ${ }^{3}$

Further, many of the first responders to the Tokyo attacks - including transit workers, police officers, emergency medical technicians (EMTs), fire fighters, and physicians - quickly became incapacitated themselves because they lacked the requisite training to function in a contaminated environment. Notably, 135 EMTs suffered acute symptoms due to exposure to the agent on victims and required medical treatment. ${ }^{4}$ Only after these effects were seen were first responders ordered to wear PPE masks.

As this example shows, a CWA incident requires specific medical response procedures to manage the risks presented by the contaminated environment. Allowing volunteer and professional responders to enter the area without PPE and training can put these responders at significant risk and could create additional victims who will delay and complicate the response.

In addition, planners must consider ways to limit the potential for the medical response to spread contamination and increase exposures. In the 1995 attacks, the medical response did not initially include patient decontamination, resulting in the contamination of medical facilities and medical staff. Notably, 23\% of the 472 hospital staff exposed to contaminated victims showed signs of sarin poisoning. ${ }^{5}$ Plans should also include development of a medical surge capacity specifically for CBR incidents.

\footnotetext{
${ }^{3}$ Tokyo Subway Attacks, HKS p. 10.

${ }^{4}$ Okumura el al., The Tokyo Subway Sarin Attack." p. 615

${ }^{5}$ Tokyo Subway Attacks, HKS p. 26
} 


\section{Resources}

The Centers for Disease Control and Prevention provides Medical Management Guidelines for Chemical Agents at http://emergency.cdc.gov/chemical/mmg.asp (Centers for Disease Control and Prevention).

\subsection{Key Planning Factors: Operational Guidelines}

\section{Key Planning Factor: Establish protocols for first responders to rapidly identify the chemical warfare agent and determine its volatility and persistence}

CWA identification precedes initiation of public health response measures; control of agent transport requires information about volatility and persistence.

\section{Description}

This Key Planning Factor is focused on the rapid identification of the CWA used in the terrorist attack and acquisition of knowledge of that agent's volatility and persistence.

\section{Significance}

CWA identification will enhance response operations by enabling responders to more effectively implement public health measures for worker safety (such as appropriate PPE), implement controls to limit secondary transport of agent, and apply medical countermeasures. Furthermore, identification of the agent and understanding of its volatility and persistence will help guide estimates of dispersal, sampling and analysis strategies, and decontamination techniques. ${ }^{6}$

In the 1995 Tokyo attack, two of the seven fatalities were station employees who attempted to clean up the liquid sarin from the floor of the subway cars. These employees did not receive adequate information about the identity and hazard of the CWA.

\section{Resources}

The DHS document, Remediation Guidance for Major Airports After a Chemical Attack, (DHS 2011) (FOUO) (FOUO), provides additional information. Note that this source recommends that results obtained through field methods be confirmed by an Organization for Prohibition of Chemical Weapons (OPCW) laboratory.

\footnotetext{
${ }^{6}$ DHS, Remediation Guidance for Major Airports After a Chemical Attack, LLNL-TR-408173-DRAFT, (2010), p. 6.
} 


\section{Key Planning Factor: Establish protocols for control of agent fate and transport after initial event}

Established protocols to control the transport of a persistent agent can help prevent additional exposures and limit further spread of the agent.

\section{Description}

This Key Planning Factor includes limiting the spread of contamination after the initial release. The utility of the several mechanisms for limiting agent spread is highly agent-dependent.

\section{Significance}

Arguably, the single most important means of reducing wide-area recovery requirements is to limit the extent of contamination within and throughout the area. Minimizing the spread of contamination will reduce remediation time and cost. After the initial release and deposition, CWA may continue to spread throughout the environment via fomite transport, reaerosolization, or volatilization. Such spreading will increase the number of people who contact the agent and thus experience incapacitating health effects. Additionally, critical infrastructure, such as hospitals and medical facilities, are likely to become contaminated. Such contamination will impact response operations and reduce the availability of key lifeline services to the region even after the response as facilities undergo decontamination.

Implementing controls and processes to limit agents spreading can reduce the extent of the contamination and thus its impact on the region's critical infrastructure and population. Further, these controls and processes will significantly reduce the risk of re-contamination of areas that have been decontaminated. Such processes may include decontamination of patients prior to their entry into medical vehicles or facilities, and decontamination of first responders and first responder vehicles.

In addition, rapid identification and securement of areas of contamination can reduce the spread of agent, as discussed in the Đetermine extent of contamination" Key Planning Factor.

\section{Resources}

The following papers discuss persistence or the fate and transport of chemical warfare agents:

Love, A. H., A. L. Vance, J. G. Reynolds, and M. L. Davisson (2004), Investigating the Affinities and Persistence of VX Nerve Agent in Environmental Matrices," Chemosphere 57, 1257-1264.

Munro, N. B., S. S. Talmage, S. G. D. Griffin, L. C. Waters, A. P. Watson, J. F. King, and V. Hauschild (1999), The Sources, Fate, and Toxicity of Chemical Warfare Agent Degradation Products, Environ. Health Perspect. 107, 933-974. 
Talmage, S. S., N. B. Munro, A. P. Watson, J. F. King, and V. Hauschild (2007a), The Fate of Chemical Warfare Agents in the Environment," Chapter 4, pp. 89-125 in T. C. Marrs, R. L. Maynard, and F. R. Sidell (Eds.), Chemical Warfare Agents: Toxicology and Treatment, 2nd Ed. John Wiley \& Sons Ltd., Chichester, West Sussex, England.

Talmage, S. S., A. P. Watson, V. Hauschild, N. B. Munro, and J. F. King (2007b), Chemical Warfare Agent Degradation and Decontamination, Current Org. Chem. 11, 285-298.

\section{Key Planning Factor: Develop protocols to determine the extent of contamination}

Established protocols can help streamline the identification of contaminated zones, the knowledge of which is crucial to both public health response and recovery.

\section{Description}

Determining the extent of contamination includes identifying contaminated versus noncontaminated areas and determining levels of agent concentration throughout the contaminated areas.

\section{Significance}

Establishing and providing training on standardized methods for using field measurements and computer-generated contamination plume maps will help set contamination zones and determine action levels.

Field measurements must follow a sampling plan that considers agent specificity, field equipment sensitivity, and exposure standards. These characteristics are interrelated. For example, more sensitive sampling methods are required for agents with lower acceptable exposure standards.

The Inter-Agency Modeling and Atmospheric Assessment Center (IMAAC) can provide computer-generated contamination plume maps, given relevant information, such as outdoor temperature, humidity, and wind speed and direction.

\section{Resources}

The DHS document, Remediation Guidance for Major Airports After a Chemical Attack (DHS 2011) (FOUO), contains several relevant pieces of information. The Guidance lists other sources of information that can be useful in determining extent of contamination, including video surveillance camera records, locations of victims, and information on movement of people and equipment through the contaminated areas. 
Additionally, the Guidance identifies pathways that may allow the spread of contamination from an indoor release to the outdoors. These pathways include HVAC exhausts, open doors and windows, and storm drains and sewers, as well as by transport on people and vehicles.

Finally, the document defines four classes of contamination zones, as shown in Table 4 .

Table 4. Four classes of contamination zones

Class 1 Zone Known or assumed to be contaminated above clearance goals (the release location and its immediate vicinity).

Class 2 Zone High likelihood of being contaminated above clearance goals (contamination seems likely due to proximity to release or known dispersion mechanisms, but definitive evidence of contamination does not yet exist).

Class 3 Zone Low likelihood of being contaminated above clearance goals (contamination is possible, but seems unlikely because of distance from release point, building layout and structure, or absence of known dispersion mechanisms).

Class 4 Zone Extremely low likelihood of being contaminated above clearance goals.

\section{Key Planning Factor: Develop public messaging and communication strategies specific to a chemical warfare agent incident}

Predefined strategies can aid timely and accurate communication and build public confidence in recovery efforts.

\section{Description}

This Key Planning Factor entails the development of CWA-specific messages for the affected population and the community at large, as well as the development of communication strategies between the multiple response and recovery agencies.

\section{Significance}

In any disaster response effort, establishing communication mechanisms is vital to the success of response operations. In a CWA incident, this significance is heightened due to the potential for the population to become exposed to the agent after the initial release by traveling through contaminated areas. Effective communications between the government and the public can minimize panic, enhance evacuations or other response measures, and ultimately reduce the number of casualties. Advance planning can facilitate timely, consistent messaging throughout the recovery process, building public trust in the process and thereby enhancing recovery. 
After recovery, a public affairs campaign can provide consistent, valuable information regarding the areas of contamination, health risks, remediation timelines, and costs. In addition, the plan should anticipate ways to meet the media demand for information. If none is provided by official sources, the media will go to alternative sources that are likely to be uncoordinated, inconsistent, and less credible.

Due to the rapid nature of CWA incidents, communicating quickly about agent identity, health risks, and locations of contamination is critical. In the Tokyo Subway attack, the identity of the CWA (sarin) was not shared with responding agencies for a full hour after identification was made, and some hospitals were never officially notified. ${ }^{7}$ This resulted in numerous medical personnel being exposed to the agent.

Advance planning can facilitate timely, consistent messaging across all levels of government, the civilian sector, and the private sector throughout the recovery process, but especially during early stages when public trust is likely to be tenuous. The FEMA's Incident Command System (ICS) (FEMA) provides a clear structure for developing and aligning communications. However, two factors might undermine ICS effectiveness during recovery operation:

- ICS effectiveness requires integration of key stakeholders, a potential challenge, as many stakeholders have yet to be identified

- The application of the ICS structure to wide-area recovery has not been adequately developed

Advance planning can also aid in developing common information-sharing systems and methods that will allow rapid adaptation of messaging strategies as public perception and/or actions change. Without these tools, messaging is likely to be delayed and inconsistent, resulting in increased levels of pubic confusion and degradation of public trust.

Such consequences were brought to light for the U.S. during the Fukushima Daiichi nuclear power plant meltdown. In this incident, the U.S. government's lack of adequate situational awareness, which led to its inability to provide information about the potential spread of contamination to the continental United States, led to increased levels of speculation and misinformation, resulting in uncertainty across the public (Carafano, 2011).

\section{Resources}

The following websites provide additional information:

The U.S. Department of Health \& Human Services provides the Public Health Emergency Response: A Guide for Leaders and Responders (U.S. Department of Health \& Human Services, 2007), with an appendix that provides basic information on CWAs; the appendix is accessible via their website at:

http://www.phe.gov/emergency/communication/guides/leaders/Documents/freo_appendixc.pdf.

\footnotetext{
${ }^{7}$ Tokyo Subway, HKS
} 
The Centers for Disease Control and Prevention provides guidance for Communicating in the First Hours: Initial Communication With the Public During a Potential Terrorism Event (U.S. Centers for Disease Control and Prevention, 2007) at http://www.bt.cdc.gov/firsthours/.

The Centers for Disease Control and Prevention provides guidance for Chemical Emergencies (U.S. Centers for Disease Control and Prevention) at http://emergency.cdc.gov/chemical/.

\subsection{Key Planning Factors: Waste Management}

\section{Key Planning Factor: Establish waste management plans for CWA- incident-specific waste, including both contaminated and decontaminated materials}

Pre-identified and pre-arranged agreements with disposal facilities can speed the removal and management of waste.

\section{Description}

This Key Planning Factor concerns initiating discussions with waste-disposal facilities, wastewater treatment facilities, and state solid-waste management authorities as part of preplanning.

\section{Significance}

Recovery operations following a large-scale release of a highly toxic chemical warfare agent will likely generate very large quantities of hazardous and non-hazardous waste. Landfills and disposal sites used by most urban areas and their waste transportations systems are not typically setup to handle this type and quantity of waste. The lack of capability could significantly increase the recovery timeline.

Predetermining disposal options for managing, transporting, and disposing of large volumes of contaminated materials is therefore essential to effective response. The process may require significant time and detailed discussions with the facilities. Solutions may include establishing staging sites, treatment options, exceptions to regulatory requirements, transportation options, and disposal options.

In addition, waste management plans should consider solutions to potentially limited laboratory capacity and the development of concise risk communications to the public (on such topics as the danger of illicit dumping, for example). 


\section{Resources}

The DHS document, Remediation Guidance for Major Airports After a Chemical Attack (DHS 2011) (FOUO), provides a description of waste management considerations. These include a review of current regulatory guidelines for waste, a description of expected degradation products and waste streams based on current decontamination technologies and federal requirements, and an appendix on Waste Management Regulations Applicable to Chemical Weapons Agent and Toxic Industrial Chemical Decontamination. Some highlights are summarized in the next paragraphs.

The Department of Homeland Security's National Response Framework (http://www.fema.gov/emergency/nrf/) directs the Environmental Protection Agency (EPA) to respond to releases of hazardous materials, including chemical warfare agents and toxic industrial chemicals, in accordance with the National Contingency Plan (NCP; ESF \#10-Oil and Hazardous Materials Response Annex, http://www.epa.gov/oem/content/lawsregs/ncpover.htm). The NCP provides affected areas a streamlined process to quickly address an incident; relief from administratively burdensome processes, such as permits for onsite treatment of hazardous wastes removed from a contaminated facility; and relief from regulatory provisions determined to be impracticable during an urgent response to a chemical warfare agent attack. (See $40 \mathrm{CFR}$ 300.415(I); 55 Federal Register 8666, 8695, March 8, 1990; and http://www.epa.gov/superfund/action/guidance/remedy/overview/removal.htm.) The NCP also provides waivers to regulatory provisions under specific circumstances.

Regulation of wastes resulting from a chemical warfare agent or toxic industrial chemical attack will primarily be directed by the Resource Conservation and Recovery Act (RCRA) for solid wastes and hazardous wastes, by the Clean Water Act if wastewater is discharged to a Publicly Owned Treatment Works (POTW) or surface water body, or by equivalent state laws. Most states are authorized by the EPA to implement the RCRA hazardous waste program in lieu of EPA implementation. Under RCRA, states so authorized can be more-but not less - stringent than the EPA; thus, for any remediation activity, state regulations and state agencies should be consulted. Most states follow the format of Federal RCRA regulations. States such as California are more stringent for wastes that are considered hazardous.

If wastewater or recovered decontamination fluids are discharged to a POTW, the waste stream must meet pretreatment requirements of a local POTW and any other acceptance criteria in the POTW permit. Discharges directly to a surface water body must meet requirements of the National Pollutant Discharge Elimination Program (NPDES) program, which are site-specific depending, in part, on the classification and criteria of the surface water body and characteristics of wastewater. Among other issues, pretreatment requirements before disposal of some wastes vary from state to state and should be verified during the planning process. Many POTWs sell sludge residues for land application in agricultural settings. The POTW must be contacted before any sewer discharge of aqueous residues from a facility-decontamination process to ensure such discharges meet facility-specific waste acceptance criteria that may be predicated on subsequent uses for sludge 


\subsection{Key Planning Factors: Recovery Planning}

\section{Key Planning Factor: Establish a decision-making process to select among environmental remediation options}

Advance planning can facilitate the time-consuming and complex process of recovery decision-making.

\section{Description}

This Key Planning Factor is concerned with establishing the decision-making process to select among available environmental remediation options, taking into consideration many complex and competing factors, including clearance goals, health risks, resource availability, costs, timelines, and waste generation.

\section{Significance}

Recovery operations following a large-scale release of a highly toxic chemical warfare agent will be time-consuming and complex. Advance planning for the decision-making process can facilitate the process of remediation so that, after clearance and any necessary reconstruction and refurbishment, normal community life can resume.

\section{Resources}

The Remediation Guidance for Major Airports After a Chemical Attack document (DHS 2011) (FOUO) contains relevant discussions on multiple topics: strategies for containment and isolation (with particular focus on strategies for use within a facility), the evaluation of decontamination capabilities, and the development of a decontamination strategy (including source reduction, selection of decontamination technologies, and evaluation of potential environmental impacts). The Guidance also discusses decontamination technologies, including surface decontamination reagents, gas and vapor technologies, and decontamination of sensitive electronic equipment and high-value items, and provides an annex with details on specific decontamination reagents, techniques, and applications.

\section{Key Planning Factor: Determine requirements for, and sources of, resources for recovery from a chemical warfare agent incident}

Pre-identified and pre-arranged agreements with neighboring jurisdictions can facilitate this process and speed the acquisition of the resources required for recovery. 


\section{Description}

This Key Planning Factor concerns advance planning that would identify requirements for, and suppliers of, resources specifically needed for recovery from a CWA incident, including sampling kits, PPE, decontaminants, decontaminant deployment equipment, and laboratory analysis capabilities.

\section{Significance}

A recovery from a chemical warfare agent incident will likely require greater quantities and types of resources than are commonly available within a region. The speed in obtaining the full measure and range of resources needed will directly impact the effectiveness of recovery.

Advance planning will help regions identify resource requirements, determine resource shortfalls, and develop a list of needs that private suppliers or other jurisdictions might fill, and then engage with the supplier and jurisdictions to ensure the ready availability of the needed resources should an incident occur. The plan should account for unsolvable resource shortfalls so they are not just assumed away." For example, planning could identify the need for government or market incentives to encourage further development of resource capabilities.

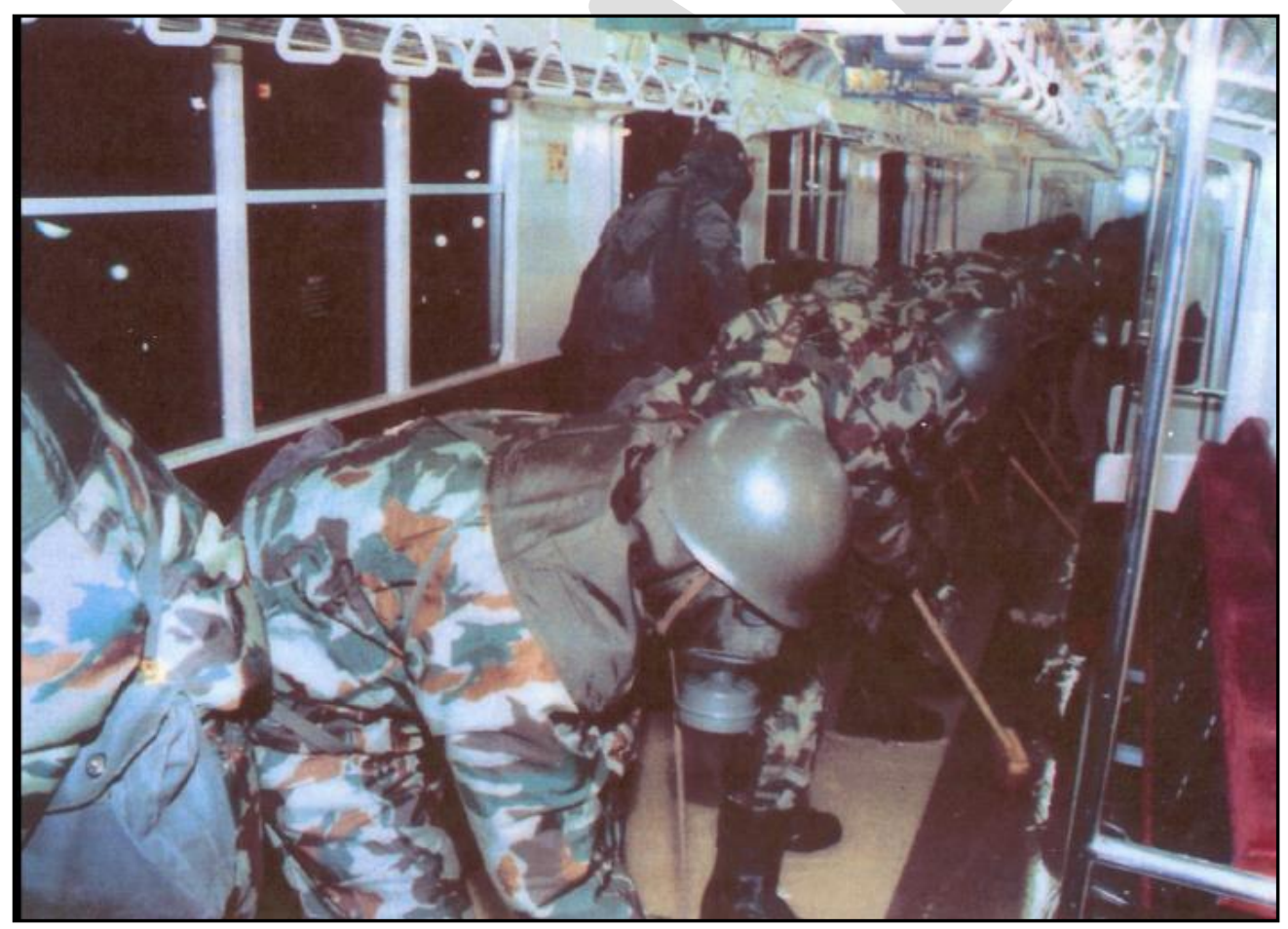

Figure 6. Tokyo Metro Fire Department hosing equipment and station platforms with decontamination solution

Key to the rapid recovery were situational awareness, pre-planning and advance joint exercises, and large well trained hazmat team integrated across multiple agencies. Photo source: Tu, 2007 


\section{Resources}

Guidance can be found in the following two sources:

Department of Homeland Security, Remediation Guidance for Major Airports After a Chemical Attack, LLNL TR-408173, (DHS, 2011)(FOUO).

U.S. Environmental Protection Agency's National Response System Flowchart (U.S. Environmental Protection Agency, 2011) at http://www.epa.gov/oem/content/nrs/snapshot.htm.

\subsection{Key Planning Factors: Clearance}

\section{Key Planning Factor: Establish a process to develop clean-up and clearance goals specific to CWA-incident remediation}

Clean-up and clearance goals drive the recovery costs and timelines.

\section{Description}

This Key Planning Factor concerns the establishment of a process to develop appropriate and reasonable clean-up and clearance goals that will balance political/social priorities and public health protection against time and cost constraints.

\section{Significance}

The selection of clean-up and clearance goals is a very complex process that requires input from technical experts and a review and understanding of data on a range of subjects, such as the CWA physical and chemical characteristics, health-based exposure guidelines, environmental conditions, composition and characteristics of the impacted areas, and other parameters. Major challenges include the absence of good dose-response data and disagreement among stakeholders regarding the adequacy of existing CWA exposure standards.

The clean-up and clearance goals are arguably the most significant drivers for the overall remediation process, strongly influencing the remediation timeline and the associated costs and resource requirements. Furthermore, timely and clear communication of exposure-based guidelines will help greatly reduce public anxiety and thereby improve post-event recovery activities.

\section{Resources}

Remediation Guidance for Major Airports After a Chemical Attack (DHS, 2011) (FOUO) describes the process for evaluation of clearance and exposure guidelines to establish clearance goals, and includes discussion of the important factors: a risk-based decision approach, exposure guidelines for chemicals of concern, characteristics of CWA of concern, a summary and definitions of existing health standards and guidelines, and a discussion of the significance of the 
release scenario and exposure analysis to the clearance decision. Some highlights are summarized below.

If a CWA terrorist incident should occur tomorrow, it is important to have ready a set of wellunderstood, defensible, health-protective exposure levels that can be assessed to develop appropriate and reasonable clearance goals for site-specific incidents. Accordingly, current CWA exposure guidelines have been summarized as pre-planning guidance. In the event of an actual incident, clearance goals established for pre-planning purposes can be further augmented with incident- and site-specific parameters and then adjusted as necessary to establish formal clearance goals.

Scientifically appropriate, well-characterized exposure guidelines must be used to ensure that human health is safeguarded without defaulting to overly conservative actions (such as cleaning to undetectable levels) that would divert limited resources without major benefits. For an actual contamination incident, site- and incident-specific factors must always be considered, and a riskbased decision process involving key stakeholders must be used.

By providing the rationale for a reasonable and scientifically supported set of procedures and health-based criteria, the Guidance document aims to give decision-makers maximum flexibility for weighing the numerous considerations (such as the safety of decontamination personnel, public health, time, funds, resources, and public perception, among others) that must be evaluated. Final decisions are made by responsible site-specific authorities, and they would reflect multiple operational factors, as well as subjective considerations of acceptable risk and socioeconomic concerns.

\subsection{Key Planning Factors: Recovery Planning for CBR and All- Hazards}

\section{Key Planning Factor: Identify and create stakeholder working groups}

Pre-identified participants streamline and add transparency to the process, as well as gain buy-in from the public.

\section{Description}

A stakeholder working group can ensure a coordinated and comprehensive planning process, and develop relationships that increase post-disaster collaboration and unified decision-making. Stakeholders collaborate to maximize the use of available resources to rebuild housing, infrastructure, schools, businesses and the social fabric of the impacted community, as well as to provide health care, access and functional support services. All community perspectives are represented in all phases of disaster and recovery planning; transparency and accountability in the process are clearly evident. 


\section{Significance}

Establishing processes and protocols for coordinated post-disaster recovery before an incident can greatly enhance the speed and success of recovery. Plans thus prepared can generally be implemented quickly, and because they incorporate local opinions, the plans meet community needs in a more holistic manner. Such plans also maximize the provision and utilization of recovery resources and build upon, or are incorporated into, the community master plan. In addition, community leaders can increase public confidence in the recovery process by following plan guidelines for measuring and communicating about progress, promoting transparency, accountability, and efficiency.

Furthermore, the stakeholder working groups should understand and have access to broad and diverse funding sources to finance recovery efforts and should provide knowledge and professional administration of external programs, which will greatly aid the recovery progress.

References: The Department of Homeland Security's National Disaster Recovery Framework (http://www.fema.gov/recoveryframework/) describes proactive community engagement, public participation, and public awareness for all hazards recovery, in addition to financial acquisition. 


\section{Comparisons to Other Scenarios}

\section{THIS SECTION WILL BE REWORKED BEFORE THE FINAL RELEASE OF THIS DOCUMENT}

This document focuses on factors for recovery from a CWA incident and uses an example scenario based on a release of a specific chemical warfare agent. This section of the document highlights important differences between recovery from large-scale CWA incidents and recovery from other large-scale events. These differences may occur in three categories:

- Differences between recovery from CBR events versus traditional all-hazards events

- Differences between recovery from CWA events versus radiological or biological events

- Differences between recovery from the example CWA scenario and scenarios that involve the release of another chemical warfare agent and/or another deposition method

\subsection{Differences between Recovery from CBR Events versus Traditional All-Hazards Events}

Response and recovery from CWA, biological, and radiological events may differ from traditional all-hazards events in several important ways. Responders are more familiar with traditional all-hazards events than with the rare CBR event. Further, compared to many largescale events (such as earthquakes and floods), physical damage may be minimal. Moreover, the hazard may be more insidious or unseen, cross-contamination may be an issue, and the contaminated area may require specialized decontamination. As a result of these factors, public anxiety may be heightened in a CBR event. Therefore, building and maintaining public confidence in governmental decisions and direction is a major consideration. Communication to the public must be honest, accurate, timely, and frequent. Coordination of local, regional, state, and federal public information is critical, particularly in providing a united message to the public.

Additional challenges posed by CBR incidents must also be factored into the mission of recovery. For example, maintaining and ensuring the health and safety of the general public while expediting remediation requires balancing risk-based remediation processes with concerns for economic recovery and revitalization. Restarting and recruiting businesses back into the impacted region so life transitions to a new normal" requires levels of trust, transparency, and stakeholder involvement well beyond those needed in traditional disaster events. Meeting these requirements may be especially challenging because many resources required for recovery (such as decontamination resources and laboratory analysis capacity) may be lacking, which may delay the government's ability to implement recovery actions. The greatest potential for achieving recovery goals lies in pre-event planning. 


\subsection{Differences between Recovery from CWA Events versus Radiological or Biological Events}

The Key Planning Factors for recovery from chemical warfare agent incidents differ from those for recovery from radiological and biological incidents primarily due to the differences in the dose-response and persistence of each type of agent. (The differences particular to the WARRP scenarios are shown in Appendix 3.) Spore-forming biological particulates, specifically $B$. anthracis, and radiological particulates can potentially contaminate vast areas of land through the propensity of the particles to persist and to re-aerosolize. In contrast, many chemical warfare agent liquids or gases will dissipate and/or degrade in the environment. Further, very small doses of biological organisms may be sufficient to cause infection, while very small amounts of a chemical agent (e.g., a few molecules) are less of a concern.

The contaminated area for any agent - chemical, biological, or radiological - would depend on the method of agent distribution and the agent persistence (persistence refers to the length of time an agent remains harmful to humans and/or other forms of life - both in terms of its toxicity and its location), leading to wide variation amongst the threat types and the particular agents. CWAs that are relatively volatile and not persistent would leave less contamination, as would biological agents that degrade rapidly in the environment. On the other hand, persistent CWAs and spore-forming biological agents (B. anthracis) would potentially have a larger area of contamination. In addition, the technologies and equipment required for chemical warfare agent incident recovery are generally more developed and available, particularly for sampling and decontamination, and the process for developing clean-up goals are more well-defined than for biological recovery.

However, the interaction of chemical warfare agents and building/outdoor materials is a very complex subject (i.e., certain agents may persist for long periods of time on some materials), which may make waste management and disposal decisions more difficult for a chemical warfare agent event as compared to a biological event.

\subsection{Differences between the Example Scenario and Other CWA Scenarios}

The particular threat incident scenario used as an example in this document is only one of many possible scenarios. An important difference among CWAs is their wide range of physical and chemical properties, such as volatility, viscosity, and reactivity (see Table 5 for examples of properties).

These properties significantly impact the recovery process because they determine both the penetration of the agent into building materials (some agents penetrate some materials more deeply than others) and the persistence of the agent in the environment (some agents persist in the environment for much longer time periods than others). In addition, the reactive mechanisms to decontaminate different agents differ from one another. These differences translate into vastly different methods for remediation, which in turn may result in large differences in the time 
required for recovery. Nonetheless, the Key Planning Factors described in this document apply to recovery from all types of CWA incidents.

Table 5: Example chemical/physical properties of chemical warfare agents

\begin{tabular}{|lccc|}
\hline Chemical/Physical Property & $\begin{array}{c}\text { Mustard } \\
\text { (HD) }\end{array}$ & $\begin{array}{c}\text { Lewisite } \\
\text { (L) }\end{array}$ & $\begin{array}{c}\text { Sarin } \\
\text { (GB) }\end{array}$ \\
\hline Boiling-point ${ }^{\circ} \mathrm{C}$ & 217 & 190 & 151 \\
\hline Melting-point ${ }^{\circ} \mathrm{C}$ & 14.6 & -18 & -56 \\
\hline Vapor pressure $\mathrm{mm} \mathrm{Hg}$ at $20^{\circ} \mathrm{C}$ & 0.072 & 0.35 & 2.1 \\
\hline Volatility $\mathrm{mg} / \mathrm{m}^{3}$ at $20^{\circ} \mathrm{C}$ & 610 & 4480 & 16,091 \\
\hline
\end{tabular}

(Source: http://cbwinfo.com [for HD, GB], Franke, S., Manual of Military Chemistry, Volume 1. Chemistry of Chemical Warfare Agents, Deutscher Militîrverlag: Berlin (East), 1967. Translated from German by U.S. Department of Commerce, National Bureau of Standards, Institute for Applied Technology, NTIS no. AD-849 866, pp. 247, 252[ for L]) 


\section{Planning Recommendations}

Initiating efforts to address these Key Planning Factors may be daunting for communities new to CBR concepts and planning. To make immediate planning progress with (always) limited funds, a community could consider approaching each KPF as a series of graduated sub-tasks or planning phases. Examples of steps in such an approach for each KPF follow.

- Establish plans for public health response specific to chemical warfare agents: Instead of attempting to establish comprehensive public health responses, start with existing HazMat procedures for chemical spill response and extend those to cover worker safety in a chemical warfare agent response. Examine existing military measures for treatment of chemical warfare agent exposure and adapt those to cover the general public.

- Establish protocols for first responders to rapidly identify the CWA and determine its volatility and persistence: Train responders on established HazMAT guidance for CWAs. Upgrade sampling equipment.

- Establish protocols for control of agent fate and transport after initial event: Start with existing protocols for establishing and controlling restricted areas. Establish protocols for rapidly establishing controls for hospital entry. Develop decontamination process for entry and exit of restricted areas.

- Develop protocols to determine extent of contamination: Begin with established procedures and equipment already in jurisdiction. Acquire additional and more sophisticated sampling equipment. Develop protocols to rapidly gain access to additional workers and equipment in an event.

- Develop public messaging and communication strategies specific to a CWA incident: Begin with existing communication plans for all hazards. Consult with subject-matter experts to develop CWA-specific message templates and protocols. Develop agreements and protocols for obtaining real-time SME expertise in an on-going event.

- Establish waste management plans for chemical warfare agent incident-specific waste: Begin with existing plans for disposal of hazardous waste; extend processes to cover waste contaminated by chemical warfare agents and their decontamination breakdown products. Identify waste disposal sites beyond the region to begin to build excess capacity.

- Establish a decision-making process to select among environmental remediation options: Train Stakeholder Working Group and decision-makers on remediation options. Develop playbook for consultation during an event. Develop a process for decisionmaking.

- Determine requirements for, and sources of, resources for recovery from a CWA incident: Based on potential CWA scenario and appropriate remediation options, develop a list of required resources. Identify sources of personnel and equipment. Develop agreements and protocols to obtain necessary resources in an event. 
- KPF Establish a process to develop clean-up and clearance goals specific to CWAincident remediation: Train Stakeholder Working Group and decision-makers on national advice. Develop protocols to consult subject matter experts real time in an event. Develop a process for decision-making.

- Identify/Create Stakeholder Working Group: The more agencies and stakeholders in a region, the more important it will be to identify working group participants and community champions, and the more involved developing a decision-making process will be. The pre-incident planning effort could be phased: 1) Identify stakeholders, 2) Socialize chemical incident scenarios and key planning needs, 3) Identify additional stakeholders, etc. 


\section{Conclusions}

A chemical warfare agent incident has the potential to disrupt life and business in a community through the potential for human casualties and land and facility contamination. Confusion and delay in response and communication can exacerbate the problem and erode public confidence. Conversely, advance planning, with particular emphasis on the Key Planning Factors identified in this document, could substantially aid the recovery process by decreasing the recovery timeline and costs, improving public health and safety, and addressing major resource limitations and critical decisions. 


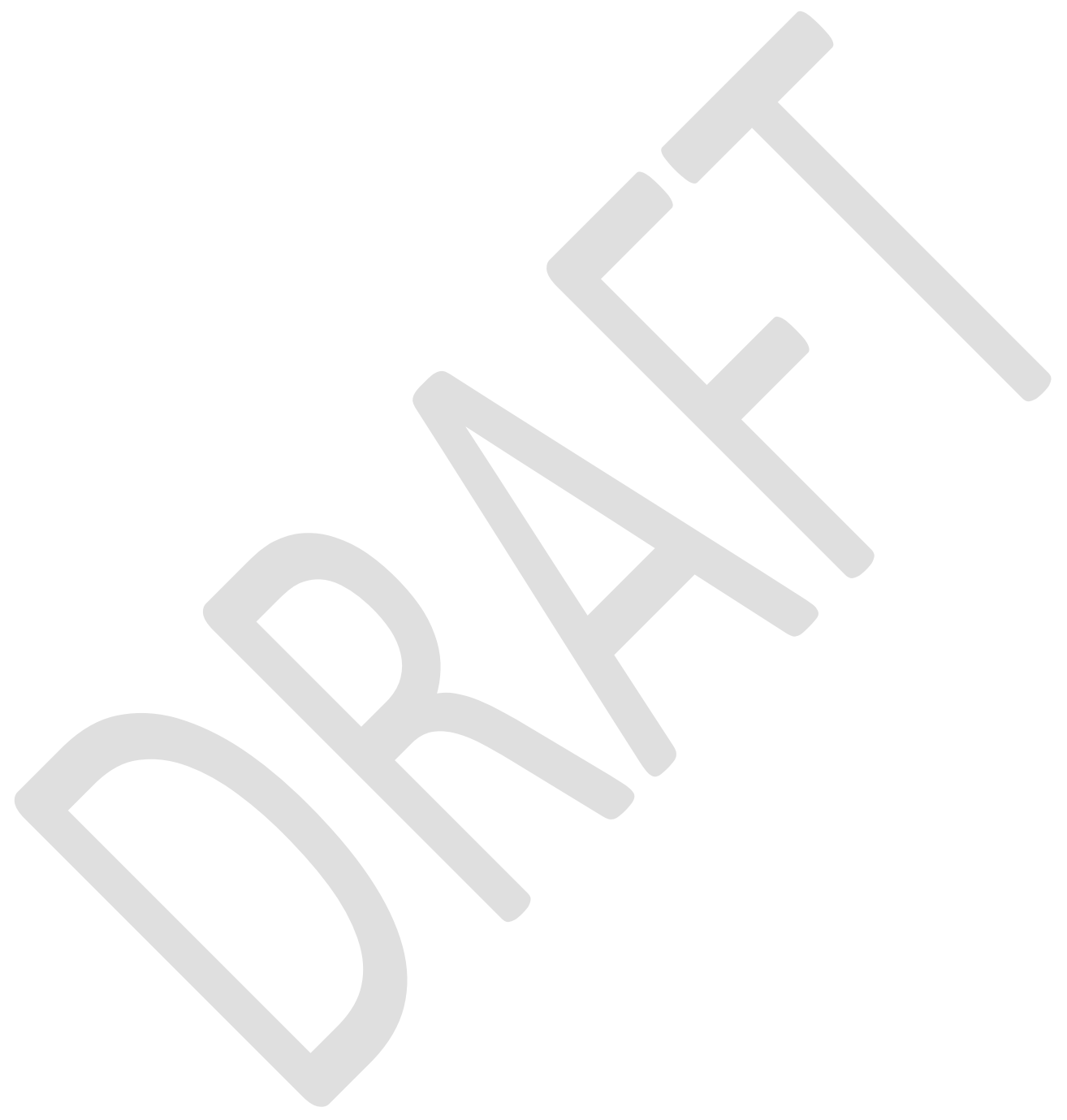

Page | 38

SAND-2012-4951 


\section{References}

Carafano, James Jay, The Great Eastern Japan Earthquake Assessing Disaster Response and Lessons for the United States (2011).

The Centers for Disease Control and Prevention, Chemical Emergencies. Available online at http://emergency.cdc.gov/chemical/.

Centers for Disease Control and Prevention, Communicating in the First Hours: Initial

Communication With the Public During a Potential Terrorism Event, (2007). Available online at http://www.bt.cdc.gov/firsthours/.

Centers for Disease Control and Prevention, Medical Management Guidelines for Chemical Warfare Agents. Available online at http://emergency.cdc.gov/chemical/mmg.asp

Department of Homeland Security, Remediation Guidance for Major Airports After a Chemical Attack, LLNL-TR-408173, (2011) (FOUO).

Department of Homeland Security, Interim Consequence Management Guidance for a WideArea Biological Attack, IBRDPLL035, (2010).

Department of Homeland Security, National Disaster Recovery Framework. Available online at http://www.fema.gov/recoveryframework/

Department of Homeland Security, National Response Framework. Available online at http://www.fema.gov/emergency/nrf/

Federal Emergency Management Agency, Comprehensive Preparedness Guide, (2010).

Franke, S., Manual of Military Chemistry, Volume 1. Chemistry of Chemical Warfare Agents, Deutscher Militîrverlag: Berlin (East), 1967. Translated from German by U.S. Department of Commerce, National Bureau of Standards, Institute for Applied Technology, NTIS no. AD-849 866, pp. 247, 252.

Einfeld, et al., Wide-Area Recovery and Resiliency Program Systems Study Report systems study, Sandia National Laboratories, (2012).

Love, A. H., A. L. Vance, J. G. Reynolds, and M. L. Davisson, Investigating the Affinities and Persistence of VX Nerve Agent in Environmental Matrices," Chemosphere 57, pp. 1257-1264 (2004),

Munro, N. B., S. S. Talmage, S. G. D. Griffin, L. C. Waters, A. P. Watson, J. F. King, and V. Hauschild (1999), The Sources, Fate, and Toxicity of Chemical Warfare Agent Degradation Products, Environ. Health Perspect. 107, pp. 933-974.

Incident Command System, Federal Emergency Management Agency. 
National Disaster Recovery Framework, Federal Emergency Management Agency, (2011).

National Preparedness Goal, Federal Emergency Management Agency, (2011).

Office of Science and Technology Policy (2006), Cleanup Decision-Making Guidance for Biological Incidents, Draft Report of the Biological Decontamination Standards Working Group, Committee on Homeland and National Security, National Science and Technology Council. Okumura, el al., The Tokyo Subway Sarin Attack.” p. 615

Presidential Policy Directive 8: National Preparedness (PPD-8), and the Interim Consequence Franco David, et al., Recovery from Chemical, Biological, and Radiological Incidents: Critical Infrastructure and Economic Impact Considerations, Sandia National Laboratories, (2012). Draft.

Spradlin, Michael, Train Derailment and Chlorine Release: Lessons Learned, South Carolina Department of Health and Environmental Control, Graniteville, South Carolina. Available online at http://www.astswmo.org/files/meetings/2006HWConference/Chlorine-Gas-Train-Derailmentand-Cleanup.pdf.

Talmage, S. S., N. B. Munro, A. P. Watson, J. F. King, and V. Hauschild, The Fate of Chemical Warfare Agents in the Environment," Chapter 4, pp. 89-125 in T. C. Marrs, R. L. Maynard, and F. R. Sidell (Eds.), Chemical Warfare Agents: Toxicology and Treatment, 2nd Ed. John Wiley \& Sons Ltd., Chichester, West Sussex, England (2007A).

Talmage, S. S., A. P. Watson, V. Hauschild, N. B. Munro, and J. F. King, -Chemical Warfare Agent Degradation and Decontamination, Current Org. Chem. 11, pp. 285-298, (2007b).

Tokyo Subway Attacks, HKS, p. 10.

Tu At, Chemical terrorism: Horrors in Tokyo Subway and Matsumoto City. Alaken, Inc., Fort Collins, Colorado (2002).

Tu At, Foxicological and Chemical Aspects of Sarin Terrorism in Japan in 1994 and 1995," Toxin Reviews, 26:231-274. 2007 (Special Issue on Chemical and Biological Warfare Agents).

USACHPPM 2008a

U.S. Department of Health \& Human Services, Public Health Emergency Response: A Guide for Leaders and Responders, (2007). The appendix with information on chemical agents is accessible via their website at:

http://www.phe.gov/emergency/communication/guides/leaders/Documents/freo_appendixc.pdf.

Watson Annetta, Linda Hall, Ellen Raber, Veronique D. Hauschild, Fredrick Dolislager, Adam H. Love, and M. Leslie Hanna, Đeveloping Health-Based Pre-Planning Clearance Goals for Airport Remediation Following Chemical Terrorist Attack: Introduction and 
Key Assessment Considerations, Human and Ecological Risk Assessment," An International Journal, 17:1, 2-56, (2011b).

Watson Annetta, Fredrick Dolislager, Linda Hall, Ellen Raber, Veronique D. Hauschild, and Adam H. Love, Đeveloping Health-Based Pre-Planning Clearance Goals for Airport Remediation Following a Chemical Terrorist Attack: Decision Criteria for Multipathway Exposure Routes, Human and Ecological Risk Assessment," An International Journal, 17:1, 5712, (2011a). 


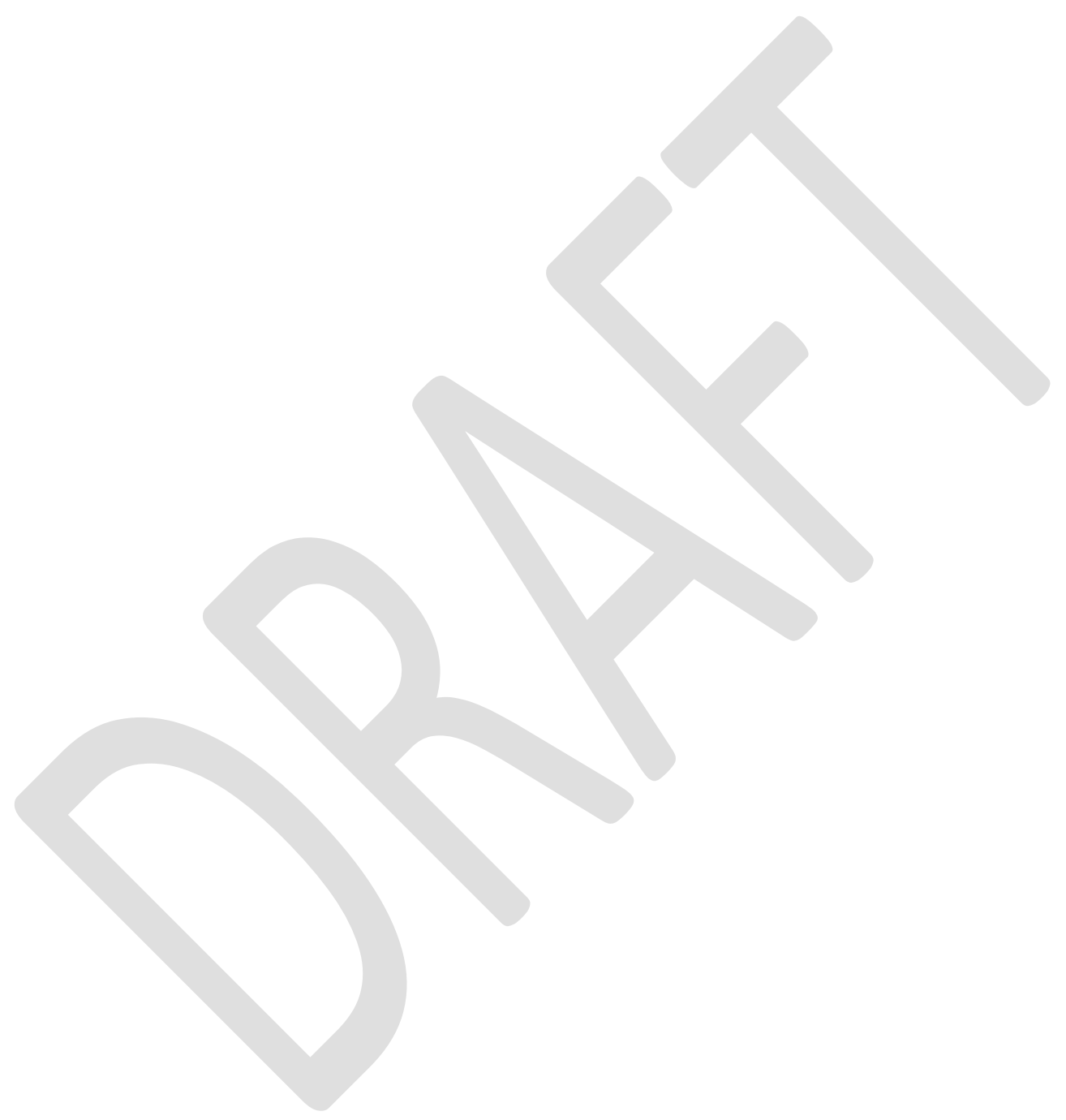

Page 42

SAND-2012-4951 


\section{Appendix 1: Comparison between Recovery Support Functions, Core Capabilities, and Key Planning Factors}

The following table shows the relationship among the National Disaster Recovery Framework (NDRF) (Federal Emergency Management Association, 2011) Recovery Support Functions, the National Preparedness Goal (FEMA, 2011) Recovery Core Capabilities, and the WARRP Key Planning Factors.

\begin{tabular}{|c|c|c|}
\hline 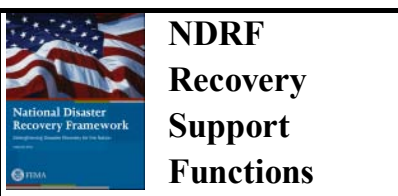 & 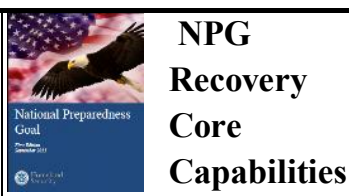 & $\begin{array}{l}\text { Wide Area Recovery \& } \\
\text { Resiliency Program Chemical } \\
\text { Key Planning Factors }\end{array}$ \\
\hline \multirow[t]{7}{*}{$\begin{array}{l}\text { Community Planning and } \\
\text { Capacity Building }\end{array}$} & \multirow[t]{2}{*}{ Planning } & $\begin{array}{l}\text { Establish protocols for control of agent fate } \\
\text { and transport after initial event }\end{array}$ \\
\hline & & $\begin{array}{l}\text { Establish Waste Management Plans for CWA } \\
\text { incident-specific waste, including both } \\
\text { contaminated and decontaminated materials }\end{array}$ \\
\hline & \multirow[t]{4}{*}{$\begin{array}{l}\text { Operational } \\
\text { coordination }\end{array}$} & $\begin{array}{l}\text { Identify and create Stakeholder Working } \\
\text { Group }\end{array}$ \\
\hline & & $\begin{array}{l}\text { Establish protocols for first responders to } \\
\text { rapidly identify the CWA and determine its } \\
\text { volatility and persistence }\end{array}$ \\
\hline & & $\begin{array}{l}\text { Establish decision-making process to select } \\
\text { among environmental remediation options }\end{array}$ \\
\hline & & $\begin{array}{l}\text { Determine requirements for, and sources of, } \\
\text { the resources for recovery from a CWA } \\
\text { incident }\end{array}$ \\
\hline & $\begin{array}{l}\text { Public Information \& } \\
\text { Warning }\end{array}$ & $\begin{array}{l}\text { Develop public messaging and } \\
\text { communication strategies specific to a CWA } \\
\text { incident }\end{array}$ \\
\hline Economic & Economic & \\
\hline \multirow[t]{3}{*}{ Health and Social Services } & \multirow[t]{3}{*}{$\begin{array}{l}\text { Health and Social } \\
\text { Services }\end{array}$} & $\begin{array}{l}\text { Establish plans for public health response } \\
\text { specific CWAs }\end{array}$ \\
\hline & & $\begin{array}{l}\text { Develop protocols to determine extent of } \\
\text { contamination }\end{array}$ \\
\hline & & $\begin{array}{l}\text { Establish process to develop clean-up and } \\
\text { clearance goals specific to CWA-incident } \\
\text { remediation }\end{array}$ \\
\hline
\end{tabular}




\begin{tabular}{|l|l|l|}
\hline Housing & Housing & \\
\hline Infrastructure Systems & Infrastructure Systems & \\
\hline $\begin{array}{l}\text { Natural and Cultural } \\
\text { Resources }\end{array}$ & $\begin{array}{l}\text { Natural and Cultural } \\
\text { Resources }\end{array}$ & \\
\hline
\end{tabular}




\section{Appendix 2: Wide-Area Response and Recovery Phases}

To accommodate a wide-range of timelines, it is useful to discuss the wide-area CBR response and recovery phases. These phases and the relationship to the National Disaster Recovery Phases are discussed in the next section.

The Department of Homeland Security's Wide-Area Recovery and Resiliency Program (WARRP) defines the response and recovery activities as follows:

- Notification

- First Response

- Characterization

- Decontamination

- Clearance

- Restoration and Reoccupation.

These activities were defined by interagency working groups from agencies such as US EPA, CDC, DHS and others. This list was then expanded to include risk assessment and planning, resulting in a set of phases better suited for a wide-area scenario. These phases do not map directly to the early- intermediate and long-term phases identified in the NDRF. Rather, the wide-area CBR response and recovery phases will span across the NDRF phases, as planning, remediation, and restoration activities continue throughout the recovery process (Office of Science and Technology Policy, 2006).

Figures A2-1 and A2-2 illustrate the correlation between the NDRF Phases and the Wide-area CBR Response and Recovery Activities and provides examples of the activities within each of the Wide-area CBR Response and Recovery phases. These activities are then described in further detail. 


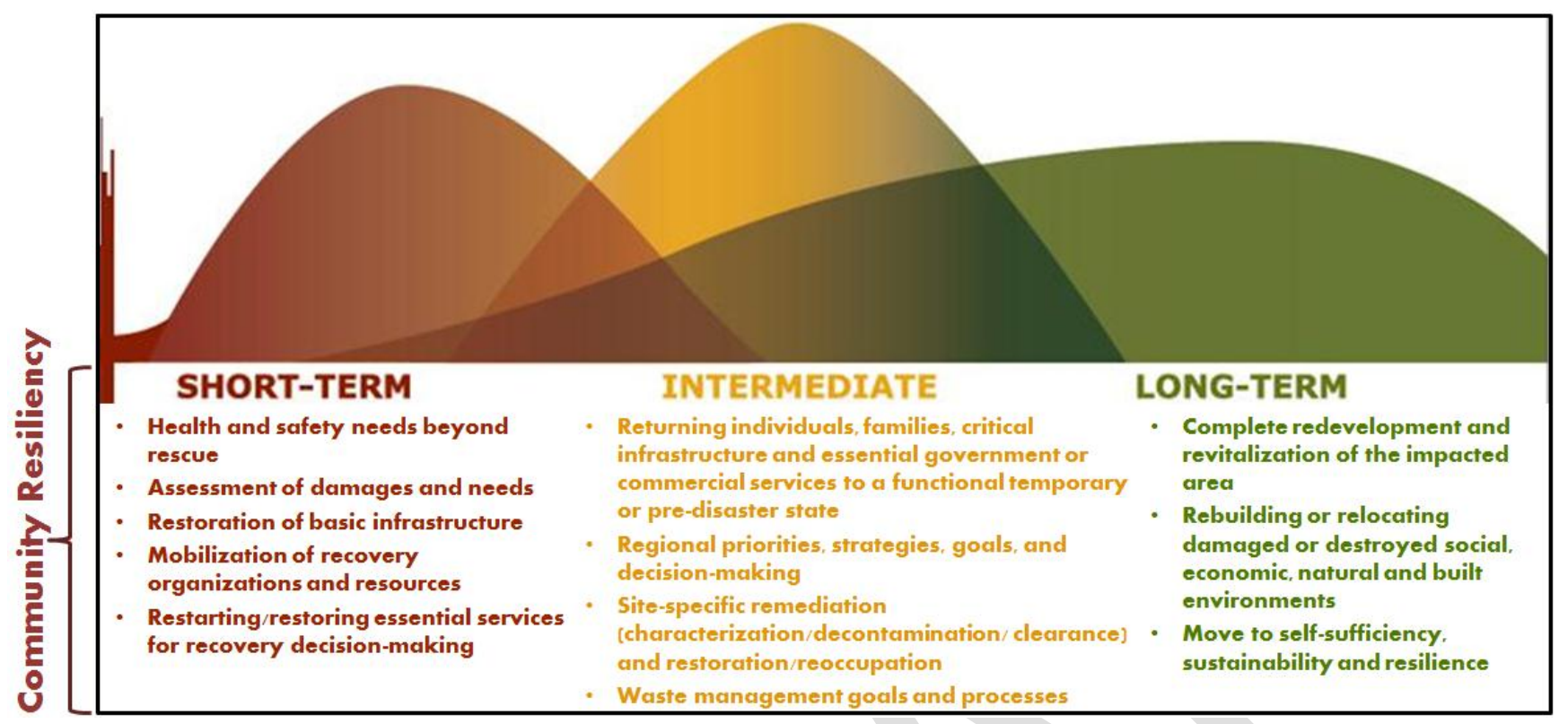

Figure A2-1. National Recovery Framework Phases

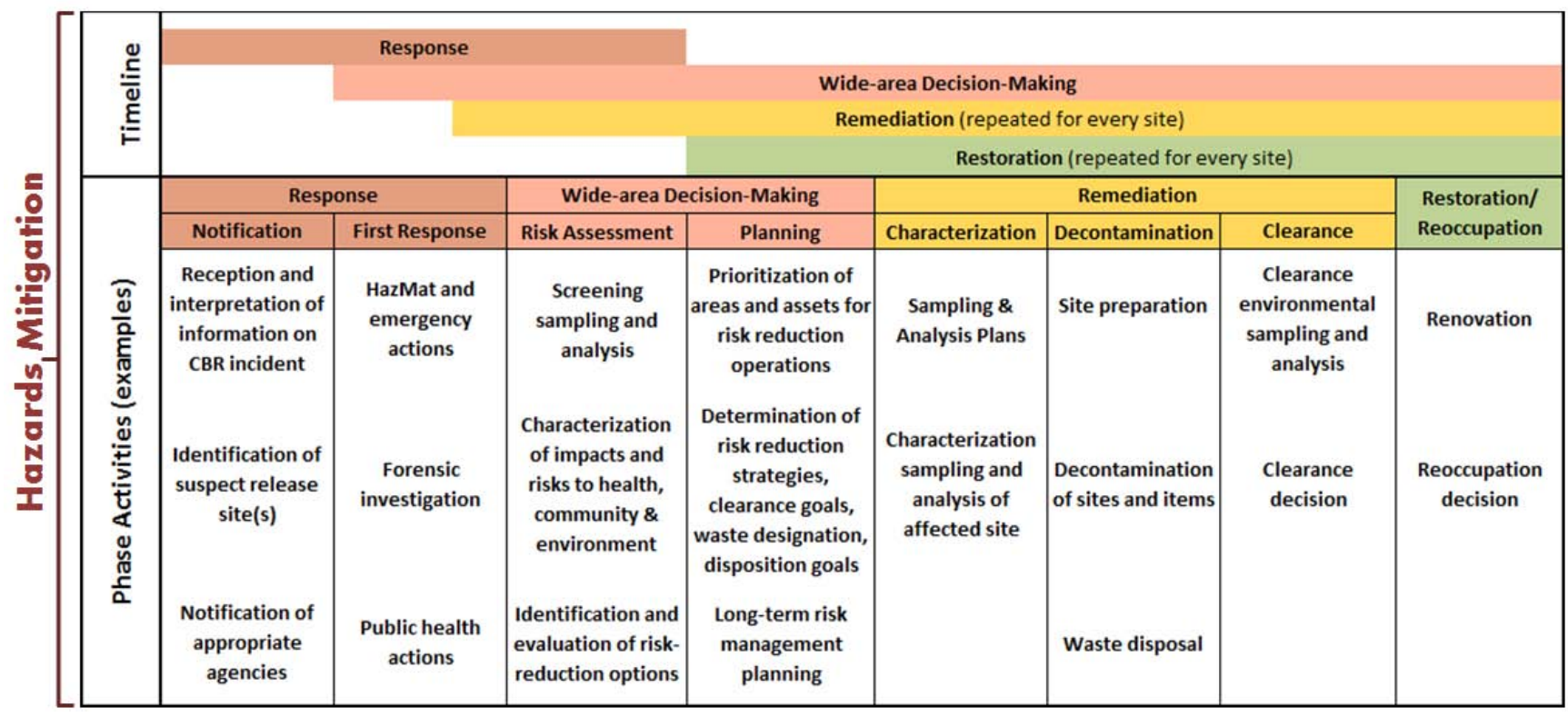

Figure A2-2. Wide-Area CBR Response and Recovery Activities

Page $\mid 46$

SAND-2012-4951 


\section{Short-Term Recovery Phase}

The short-term phase initiates Response, which begins with the identification of an incident, continues with notification and emergency first-response phases, and continues for as long as emergency personnel are present. Early response actions, following identification of the CWA include but are not limited to notification of appropriate agencies to the key information and potential risks, the identification of suspected release sites, HAZMAT and emergency actions, forensic investigation, public health actions, screening sampling, determination of agent type and concentration, the establishment of a Unified Command, and risk communication. Actions in this period are likely to be conducted with minimal or incomplete information on the nature and extent of the event.

Notification Activities: One or more Emergency Operations Centers (EOCs) identifies an incident or has knowledge of a threat regarding an incident. Information gathering and dissemination to all relevant agencies are the main tasks.

First-Response Activities: Central concerns are rescuing, decontaminating, evacuating, and, if needed, isolating or quarantining or otherwise managing affected persons; taking public health measures necessary for persons who were potentially exposed; containing areas of contamination and mitigating conditions that pose an immediate threat to human health (such as explosion in the case of an explosive release); minimizing the spread of contamination; and containing and investigating the crime scene. This phase begins by activating a Unified Command, law enforcement and emergency operations personnel [e.g., security, medical, and hazardous materials (HazMat) teams, as needed], and continues as long as emergency personnel are present. The agent is identified and assessed for viability, toxicity, infectiousness, and other characteristics using reliable methods [e.g., an Environmental Chemical Laboratory Response Network (ECLRN) laboratory]. Initial public health assessment can assist in identifying potential sources of contamination, locations of contaminants, contaminated media, and exposure scenarios.

\section{Intermediate-Term Recovery Phase}

The intermediate-term engages technical experts and stakeholders to perform on-going assessment and evaluation of risks and to prioritize and make decisions for the wide-area context. The intermediate term also begins site-specific remediation and restoration, which includes characterization, decontamination, and clearance, as well as restoration/reoccupation of individual indoor or outdoor sites.

Risk Assessment Activities: The focus is on performing screening environmental sampling to determine the extent and levels of contamination; assessing environmental characteristics of the CBR agent that affect its subsequent spread, such as its persistence on surfaces and potential for further spread, e.g. through tracking, vaporization, reaerosolization, etc.; and characterizing and 
communicating the impacts and risks in terms of the potential health consequences to humans and harm to the environment. An environmental risk assessment for remediation purposes is conducted. Collected information is evaluated to identify and evaluate risk-reduction options for indoors and outdoors. On-going risk assessment includes long-term environmental and public health monitoring.

Planning Activities: The focus is on engaging stakeholders in order to develop regional recovery priorities and strategies for risk reduction, to prioritize the areas and facilities consistently within that framework, to set specific clearance goals, to adopt waste designation and disposition goals, and to develop long-term risk management plans (including long-term environmental and public health monitoring). Because of critical access issues and the likelihood of recontamination, certain outdoor areas may be given priority. Clearance goals are likely to be set separately for indoor facilities, outdoor areas, and water-distribution systems. The decisionmaking, assessment, and monitoring continue throughout the remediation process.

Characterization Activities: The focus is on planning and performing characterization environmental sampling to determine the extent and levels of contamination at each particular site. Collected information is evaluated to determine what types and degrees of decontamination are needed for this site.

Decontamination Activities: The focus is on preparing and implementing detailed plans for decontaminating those contaminated items, areas, and facilities deemed suitable for such treatment. For some CBR agents that do not remain viable for lengthy periods in the environment, monitored natural attenuation may be an adequate decontamination option. In cases where contamination is not extensive or the agent is not environmentally persistent, application of surface decontaminants or other methods of medical infection control may be effective. For extensive contamination, especially in indoor areas by agents such as $B$. anthracis, fumigation is an option. In those cases, source reduction is considered, which involves removing salvageable and non-salvageable items, and pre-cleaning surfaces to reduce contaminant load. Scenario- and site-specific decontamination reagents and delivery systems are selected, and all systems are pretested before carrying out chemical treatments.

\section{Long-Term Recovery Phase}

Decontamination Activities: In the case of a wide-area contamination involving potentially hundreds to thousands of buildings and outdoor sites, the remediation and restoration phases may stretch into the long term, particularly since the decontamination and clearance phases will likely require the use of scarce decontamination and laboratory resources.

Clearance Activities: The focus is on determining whether to reoccupy an area or facility and re-establish normal activities. Appropriate experts review and evaluate key data, such as characterization and clearance environmental sampling results, decontamination process parameters and verification results, quality assurance and quality control (QA/QC) data, and 
other relevant information. Clearance criteria are applied to judge the effectiveness of any decontamination processes that may have been used. Final decisions on clearance are made by local, state, or Federal public health officials, or government agencies, depending on site-specific jurisdictional authorities.

Restoration \& Reoccupation Activities: The focus is on preparing an area or facility for reoccupancy, reuse, or refurbishment, such as renovating indoor areas that have undergone fumigation. Restoration can include upgrading equipment in critical infrastructure to mitigate the effect of possible future attacks. 


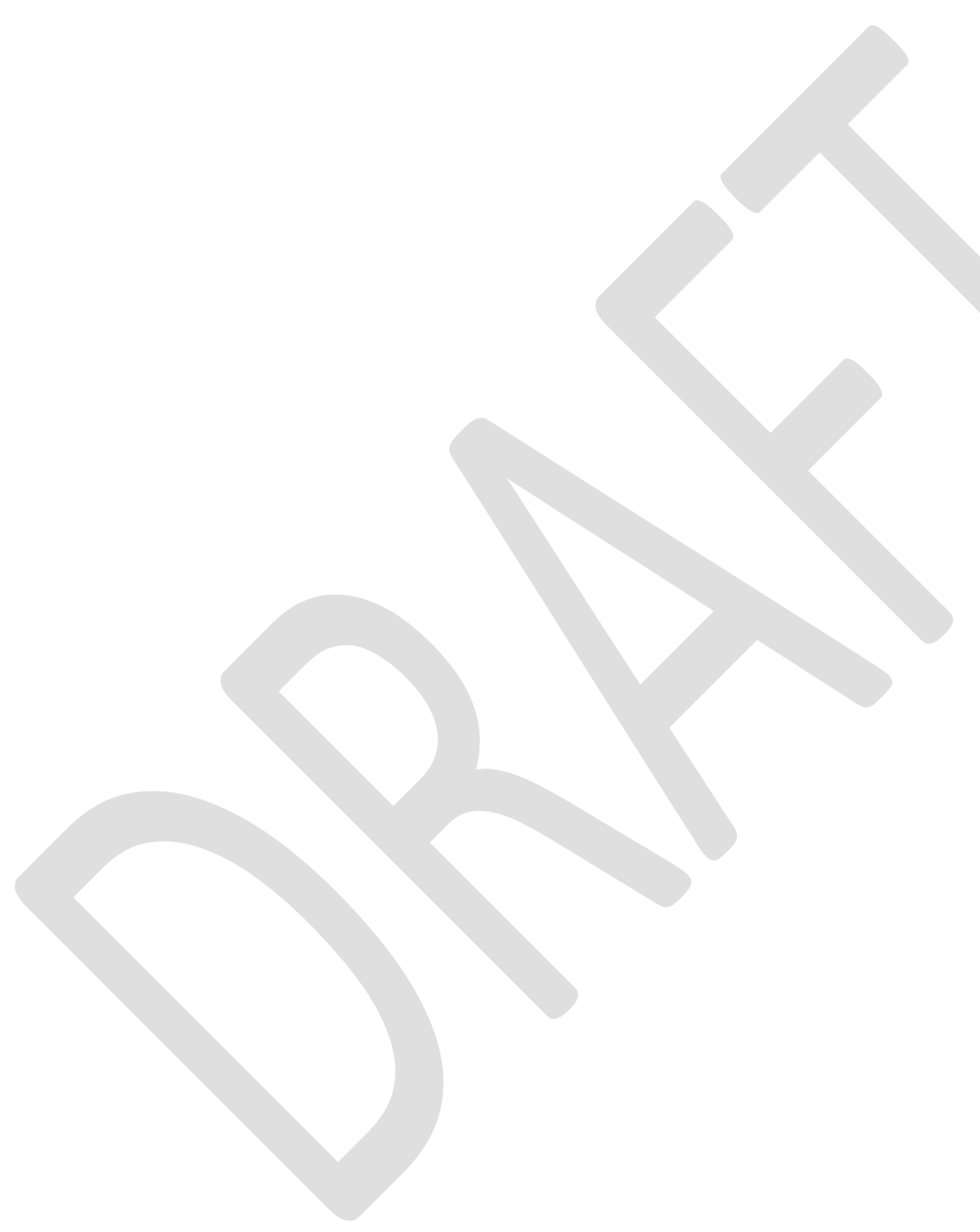




\section{Appendix 3: Comparison of Chemical, Biological, and Radiological Scenarios in Key Planning Factors for Recovery Document Set ${ }^{8}$}

\begin{tabular}{|c|c|c|c|}
\hline Issue & $\begin{array}{c}\text { Chemical Scenario } \\
\text { (Agent Yellow) }\end{array}$ & $\begin{array}{l}\text { Biological Scenario } \\
\text { (Bacillus anthracis) }\end{array}$ & $\begin{array}{c}\text { Radiological Scenario } \\
\text { (aerosolized Cesium-137) }\end{array}$ \\
\hline Agent Properties & Liquid/vapor, moderate volatility. & $\begin{array}{l}\text { Aerosolized spores can reaerosolize and spread } \\
\text { contamination and increase exposure. }\end{array}$ & $\begin{array}{l}\text { Aerosolized particulates (particle sizes } \\
\text { varying with explosive delivery) can } \\
\text { spread contamination and increase } \\
\text { exposure. }\end{array}$ \\
\hline Persistence & $\begin{array}{l}\text { Agent Yellow is persistent on porous surfaces, } \\
\text { the persistence depending on environmental } \\
\text { conditions. }\end{array}$ & $\begin{array}{l}\text { B. anthracis spores are highly persistent, with } \\
\text { potential to remain viable for many decades. }\end{array}$ & $\begin{array}{l}\text { Cesium-137 has a half-life of } 30.17 \text { years } \\
\text { and will be highly persistent. }\end{array}$ \\
\hline $\begin{array}{c}\text { Recognition of a CBR } \\
\text { Event }\end{array}$ & $\begin{array}{l}\text { With immediate symptoms, recognition will } \\
\text { be likely within minutes to hours, and source } \\
\text { area will be known. }\end{array}$ & $\begin{array}{l}\text { With -early" BioWatch detection and } \\
\text { recognition, response will likely be initiated days } \\
\text { ( } 8 \text { to } 36 \text { hrs) later. Source area will not be known } \\
\text { initially. Detection may occur by stationary } \\
\text { monitoring which exists in limited areas. }\end{array}$ & $\begin{array}{l}\text { The explosion would be immediate, but } \\
\text { recognition of accompanying radiological } \\
\text { contamination would require detection } \\
\text { and confirmation that could delay } \\
\text { response. }\end{array}$ \\
\hline $\begin{array}{l}\text { Time to Symptoms } \\
\text { (Delay in Response) }\end{array}$ & $\begin{array}{l}\text { Immediate symptoms for Lewisite; Sulfur } \\
\text { Mustard symptoms hours later. }\end{array}$ & $\begin{array}{l}\text { Symptoms present in days, response likely } \\
\text { initiated days later. }\end{array}$ & $\begin{array}{l}\text { Acute radiation poisoning possible in } \\
\text { limited areas, long term cancer risks } \\
\text { increase. }\end{array}$ \\
\hline Sampling Capabilities & $\begin{array}{l}\text { Specialized teams from EPA and contractors } \\
\text { may be available. }\end{array}$ & $\begin{array}{l}\text { Specialized teams from EPA and contractors may } \\
\text { be available. }\end{array}$ & $\begin{array}{l}\text { DOE has deployable radiological } \\
\text { monitoring teams, and EPA also has key } \\
\text { expertise. }\end{array}$ \\
\hline $\begin{array}{l}\text { Analytical } \\
\text { Capabilities }\end{array}$ & $\begin{array}{l}\text { Real-time detection available for high } \\
\text { concentrations, but not effective for lower } \\
\text { concentrations. Laboratory analytical } \\
\text { capacities may be limited in a wide-area event; } \\
\text { a mobile laboratory is available. }\end{array}$ & $\begin{array}{l}\text { For } B \text {. anthracis there is a validated sampling and } \\
\text { identification protocol. Laboratory analytical } \\
\text { capacities may be limited in a wide-area event; a } \\
\text { mobile laboratory is available. }\end{array}$ & $\begin{array}{l}\text { Radiological field detectors available with } \\
\text { speciation capacity. }\end{array}$ \\
\hline
\end{tabular}

\footnotetext{
${ }^{8}$ Issues summarized by chemical, biological, or radiological contamination for scenarios prepared in support of DHS WARRP activities. Page $\mid 51$ 


\begin{tabular}{|c|l|l|l|}
\hline Issue & \multicolumn{1}{|c|}{$\begin{array}{c}\text { Chemical Scenario } \\
\text { (Agent Yellow) }\end{array}$} & $\begin{array}{c}\text { Biological Scenario } \\
\text { (Bacillus anthracis) }\end{array}$ & $\begin{array}{c}\text { Radiological Scenario } \\
\text { (aerosolized Cesium-137) }\end{array}$ \\
\hline $\begin{array}{c}\text { Medical } \\
\text { Countermeasures }\end{array}$ & $\begin{array}{l}\text { Limited ability to control initial exposure, } \\
\text { remove clothing and wash off remaining } \\
\text { agent. }\end{array}$ & $\begin{array}{l}\text { Limited ability to control initial exposure, } \\
\text { remove clothing and wash off remaining agent; } \\
\text { prophylaxis (Cipro or other antibiotics) available } \\
\text { for secondary exposure. }\end{array}$ & $\begin{array}{l}\text { Limited ability to control initial exposure, } \\
\text { however explosion would be primary } \\
\text { cause of injury or fatalities. }\end{array}$ \\
\hline $\begin{array}{c}\text { Decontamination } \\
\text { Options }\end{array}$ & $\begin{array}{l}\text { Monitored natural attenuation with time or } \\
\text { addition of heat (volatilization), deactivation } \\
\text { with pH-amended bleach, disposal of polymer } \\
\text { materials (rubber, vinyl tiles, etc...) that have } \\
\text { absorbed the agent. }\end{array}$ & $\begin{array}{l}\text { Disinfection with surface applied liquids (pH- } \\
\text { amended bleach, hydrogen peroxide peroxyacetic } \\
\text { acid, liquid chlorine dioxide...) or fumigants } \\
\text { (vaporous hydrogen peroxide, chlorine dioxide } \\
\text { gas). }\end{array}$ & Physical removal. \\
\hline Clearance Goals & $\begin{array}{l}\text { No Federal clearance goals established; } \\
\text { California has established goals for the State. }\end{array}$ & $\begin{array}{l}\text { No Federal clearance goals established, } \\
\text { historically used no viable spores in surface wipe } \\
\text { samples. }\end{array}$ & $\begin{array}{l}\text { No numerical clearance goal established; } \\
\text { Optimization" basis for clearance goals. }\end{array}$ \\
\hline
\end{tabular}




\section{Appendix 4: Chemical Agent Toxicity}

The more toxic a chemical, the smaller the amount of chemical required to cause harm. This table compares the lethal concentrations in parts per million ( $\mathrm{ppm}$ ) for acute (all-at-once) exposures to some chemical weapons and some common industrial chemicals.

\begin{tabular}{|c|c|}
\hline Chemical Agent & $\begin{array}{l}\text { Approx. Lethal Concentration* } \\
\text { (in ppm) }\end{array}$ \\
\hline \multicolumn{2}{|c|}{ Some chemical warfare agents } \\
\hline Sarin (GB) & 36 \\
\hline Hydrogen Cyanide** & 120 \\
\hline \multicolumn{2}{|c|}{ Some toxic industrial chemicals } \\
\hline Chlorine** & 293 \\
\hline Hydrogen chloride & 3,000 \\
\hline Carbon monoxide & 4,000 \\
\hline Ammonia & 16,000 \\
\hline Chloroform & 20,000 \\
\hline Vinyl chloride & 100,000 \\
\hline \multicolumn{2}{|c|}{$\begin{array}{l}{ }^{*} \text { Based on } \mathrm{LC}_{50} \text { values in laboratory rats: exposure concentration for } 60 \text { minutes at which } 50 \% \\
\text { of rats would die. Rats are used for toxicology tests in part because of similarity to humans, bu } \\
\text { they are likely to be more susceptible because they have higher metabolisms. }\end{array}$} \\
\hline \multicolumn{2}{|c|}{ **Used both as chemical weapons and as industrial chemicals } \\
\hline
\end{tabular}




\section{Distribution}

2

$1 \quad$ MS9003

Alex Roesler

08112

$1 \quad$ MS9001

Howard Hirano

08110

$1 \quad$ MS9001

Peter Davies

08100

$1 \quad$ MS0899

RIM-Reports Management 9532 (electronic copy) 
Page | 57

SAND-2012-4951 
(17) Sandia National Laboratories 